University of Louisville

ThinkIR: The University of Louisville's Institutional Repository

Electronic Theses and Dissertations

8-1995

\title{
Global coherence and the teaching of composition.
}

Frank A. Davis 1953-

University of Louisville

Follow this and additional works at: https://ir.library.louisville.edu/etd

\section{Recommended Citation}

Davis, Frank A. 1953-, "Global coherence and the teaching of composition." (1995). Electronic Theses and Dissertations. Paper 318.

https://doi.org/10.18297/etd/318

This Doctoral Dissertation is brought to you for free and open access by ThinkIR: The University of Louisville's Institutional Repository. It has been accepted for inclusion in Electronic Theses and Dissertations by an authorized administrator of ThinkIR: The University of Louisville's Institutional Repository. This title appears here courtesy of the author, who has retained all other copyrights. For more information, please contact thinkir@louisville.edu. 
GLOBAL COHERENCE AND THE TEACHING OF COMPOSITION

\author{
By \\ Frank A. Davis \\ B.A., Western Kentucky University, 1976 \\ M.A., University of Arizona, 1982

\begin{abstract}
A Dissertation
Submitted to the Faculty of the

Graduate School of the University of Louisville

in Partial Fulfillment of the Requirements

for the Degree of
\end{abstract} \\ Doctor of Philosophy \\ Department of English \\ University of Louisville \\ Louisville, Kentucky
}

August 1995 
Global Coherence and the Teaching of Composition

By

Frank A. Davis

B.A., Western Kentucky University, 1976

M.A., University of Arizona, 1982

A Dissertation Approved

4 November 1994

By the Following Reading Committee

Dennis Hall, Director

Thomas Van

R.H. Miller

John Robinson

H. Edward Richardson 


\begin{abstract}
Within the discipline of rhetoric and composition, the notion of coherence possesses the status of sine qua non, yet this notion has been treated unevenly or been taken for granted, much as the process of composing itself was taken for granted for the better part of this century. This practice has occurred for the following reasons: coherence is the "unmarked" condition of speech, and by transfer, also the "unmarked" condition of writing; the surface language of a composition has traditionally been the focus for solving any problems of coherence; and, collateral disciplines have not been sufficiently drawn upon in understanding the global nature of those elements which cohere a successful composition.

The author posits that virtually all cohering elements fall within three global categories, linguistic, cognitive, or contextually salient, and, moreover, that these cohering elements occur on a continuum that extends from the explicit to the implicit. The linguistic category includes co-reference, repetition, anaphora, cataphora, and ellipsis. The cognitive category includes the given/new relationship, Gestalt, parallel distributed processing, and central cognitive processes. The contextually salient category
\end{abstract}


includes warrants, register, central metaphors, sociological models, and epistemological frames.

Such an approach redistributes the burden of our understanding coherence from the surface language of a composition to a tripartite focus, including not only surface language, but also elements beneath it and beyond it, thus providing a manageable framework for the analysis of coherence, commonly recognized as the most essential quality of any composition.

The study concludes with implications this approach has for the teaching of composition and rhetoric in the college classroom. 


\section{ACKNOWLEDGMENTS}

First, I must thank Rosario Drucker Davis for her unflagging support throughout this project. Next, deepest thanks must be expressed to Dennis Hall--he advised me upon my entry into the doctoral program, critiqued my teaching, served as sounding board for my ideas, and chaired my dissertation committee. I cannot thank this scholar and gentleman enough.

Jean Zukowski/Faust and John Mayher must be thanked for their pedagogical example of the composition-centered classroom. I must thank Robert de Beaugrande and Robert st. Clair for their demonstrating the essential role linguistics plays in coherence and in composition. John Robinson revealed to me the fascinating interplay among language, cognition, and structure, and for this I continue to be grateful.

Thanks must also go to my chairperson, Mike Anzaldúa, for the encouragement, advice, and creative scheduling he offered me, and to walter Tucker, who early on showed me how to learn, with and without a book. 
Abstract . . . . . . . . . . . . . i ii-iv Acknowledgments. . . . . . . . . . . . . . . v

Chapter I: Background of Global Coherence. . . . . . . 1

A Historical Sketch of Global Coherence . . . . . . 1

Contemporary Research on Global Coherence... . . . 3

Three Lines of Inquiry. . . . . . . . . . . 15

Chapter II: The Linguistic Perspective . . . . . . 31

Overview of the Linguistic Perspective. . . . . . 31

Linguistic Elements of Global Coherence . . . . . 62

An Explicit-Implicit Continuum. . . . . . . 70

Chapter III: The Cognitive Perspective . . . . . . 78

Overview of the Cognitive Perspective... . . . 78

Cognitive Elements of Global Coherence. . . . . . 92

An Explicit-Implicit Continuum. . . . . . . . 102

Chapter IV: The Contextual Salience Perspective. . . 108

Overview of the Contextual Salience Perspective. . 111

Contextually Salient Elements of Global Coherence . 130

An Explicit-Implicit Continuum. . . . . . . . 134

Chapter V: Syzygy. . . . . . . . . . . . . . 140

A Visual Metaphor of Global Coherence . . . . . 145

Pedagogical Implications. . . . . . . . . . 147

syzygy. . . . . . . . . . . . . . . . . 153

Appendix I . . . . . . . . . . . . . . . 156

Appendix II. . . . . . . . . . . . . . 176

vita . . . . . . . . . . . . . . . . 181 


\section{CHAPTER I}

\section{BACKGROUND OF GLOBAL COHERENCE}

\section{A Historical Sketch of the Concept}

Interest in a coherent text dates from the classical period of rhetoric. Aristotle, while not using the term coherence or global coherence, clearly presupposed it in his Poetics when describing the "organic whole" as "the structural union of the parts [of the text] being such that, if any one of them is displaced or removed, the whole will be disjointed and disturbed" (35). Horace exhorts "let your work be what you will, provided only it be uniform and a whole" (68).

Longinus, in on the sublime, tells us more: ". . we see skill in invention, and due order and arrangement of matter, emerging as the hard-won result not of one thing nor of two, but of the whole texture of the composition" (43). Longinus continues:

Now, there inhere in all things by nature certain constituents which are part and parcel of their substance. It must needs be, therefore, that we shall find one source of the sublime in the systematic selection of the most important elements, and the power of forming, by their mutual combination, what may be called one body. (69)

Longinus places particular emphasis on the notion that "there inhere in all things by nature certain constituents which are part and parcel of their substance." However, he 
does not elaborate on these "certain constituents," nor on how they "inhere in all things by nature." Throughout this study in global coherence, I shall seek to identify these certain constituents and indicate how they cohere a composition.

According to the Oxford English Dictionary, the first recorded use of the word coherence in English occurred in 1604 when Robert Cawdrey published A Table Alphabeticall of Hard English Words, in which he listed, "cohaerence, ioning, and vniting together" (30); in 1659, Thomas Fuller used the word in The Appeal of Injured Innocence: "A naked sentence. - disarmed of the coherence before and after it" (5); and in 1678, Thomas Hobbes made use of the word in Decameron Physiologicum: or, Ten Dialogues of Natural Philosophy: ". . - the points of contact will be many (which make the coherence stronger)" (ix. 108).

Webster's Third New International Dictionary defines coherence as "the quality or state of cohering . . systematic or methodical connectedness or interrelatedness esp. when governed by logical principles" (440); the same dictionary defines global as "emphasizing a totality rather than the constitutive elements of a totality... comprehensive. . total" (965). Accordingly, for the purpose of this study, I offer the following working definition of the term global coherence: the comprehensive, systematic connection of constitutive elements of a 
composition or essay, with a consistent emphasis on both the totality of the text and on the interrelatedness of its constituents.

\section{Contemporary Research on Global Coherence}

A review of related scholarship indicates that the concept of coherence has been treated in varying degrees and from different perspectives in composition and rhetoric, with the notion of global coherence often alluded to or assumed, but rarely addressed directly or in detail. For example, the CCCC Bibliography of Composition and Rhetoric, 1987 lists "Teaching Coherence Techniques" as a subject in its index, yet of 265 entries in the indicated section, one entry deals with unity, another entry deals in part with organic form, and none deals with coherence or global coherence (Lindeman); Research on Written Composition, a comprehensive review of over twenty years of research, does not address coherence or global coherence (Hillocks); the 1987 Bedford Bibliography for Teachers of Writing lists two articles and no books on coherence or global coherence (Bizzell \& Herzberg).

Richard Lanham, in his Handlist of Rhetorical Terms, offers several related terms--composition, eutrepismus, ordo, ordinatio, synathroesmus, and taxis--but each is concerned with order, arrangement, or the putting together of words, sentences, or parts of an oration one with the 
other, not with their interrelatedness at the global level. Lanham writes:

Although extensively discussed in its component details, the form of the oration [the text as a whole] has not received the scholarly attention it deserves, as the form that has governed a good deal of writing and speaking not specifically rhetorical. (112)

Linda Woodson, in her Handbook of Modern Rhetorical Terms, does not list coherence or global coherence (nor unity nor organic form, which are traditionally associated with belles lettres). She does list form, defining it as "The structure of the complete piece of discourse or of its identifiable parts" and likens it to dispositio in classical rhetoric (25). Such a definition, while naturally focusing on the structure of the text, fails to focus on the comprehensive, systematic interrelatedness of the text's constitutive elements.

The topic of coherence has also been dealt with in varying degrees and from different perspectives by authors of composition textbooks. Donald Davidson, in his American Composition and Rhetoric, first published in 1939, devotes thirty-three pages to developing coherence in a composition, giving examples from distinguished writers which illustrate different methods of coherence; Davidson emphasizes cohesion between the constituent parts of a composition while also emphasizing the work as a whole, noting kinds of overall order--"natural," "logical," and "instinctive" (39-40)--as well as noting transitional devices between and within 
paragraphs and emphasizing concepts such as "guiding purpose" (37) and "free association" (41). Davidson then provides two detailed methods for achieving a coherent essay, followed by exercises for developing coherence. The various authors of the Harbrace College Handbook, published in numerous editions since 1941, devote thirty-three pages to coherence: all but one of these pages focus on coherence at the sentence level.

James M. McCrimmon, author of the widely used writing with a Purpose, published from 1957 to the present, devotes five pages to coherence. Although Mccrimmon offers the student writer sample passages of several paragraphs which are annotated for coherence throughout each passage, he clearly focuses on coherence at the paragraph level, defining coherence as "the integration of sentences within a paragraph" (446). For McCrimmon, paragraphs are "compositions in miniature" (81), and "The best way to get coherence in a paragraph is to think in paragraphs" (92).

Donald Stewart, in his The Versatile Writer (1986), does not index coherence, clarity, form, or unity, nor does he have any sections dealing with these or related concepts. In all fairness to stewart, he does draw heavily from classical arrangement to foster coherence.

Maxine Hairston and John Ruszkiewicz, in The Scott, Foresman Handbook for Writers (1991), also do not index coherence, form, or unity, but they do address clarity, 
stating that the "first prize always goes to clarity" (183). Hairston and Ruszkiewicz devote twenty-five pages to clarity, but they do not address coherence at the essay level, instead focusing almost exclusively on coherence within, and not between, single paragraphs.

Unfortunately, errors of coherence have also been treated unevenly in composition handbooks, which further compounds the challenge of teaching students to write globally coherent compositions. Indeed, errors of coherence have been treated, and consequently marked, indiscriminately. The marking of coherence errors has traditionally taken place on errors at the sentence level, as the following examples from the Harbrace College Handbook illustrate:

a. When discussing creativity, a person's ability to finish a pun is stressed by John E. Gibson.

b. When discussing creativity, John E. Gibson stresses a person's ability to finish a pun. (Hodges \& Whitten 250)

$[1: 2]$

a. We bought gasoline in Arkansas at a small country store which cost $\$ 3.12$.

b. At a small country store in Arkansas, we bought gasoline which cost $\$ 3.12$. (Hodges \& Whitten 252)

Of course, the "a" sentences above do have problems, and the "b" versions are more coherent, but Hodges and Whitten's 
restricting the marking of "coherence" errors to the sentence level not only fails to reflect the various elements of global cohereonce operating throughout a composition, but such treatment of coherence errors also restricts the student writer's level of thought--often to only the literal level--thus influencing students to think at this most basic level. However, composition teachers encourage their students to engage in and articulate at various levels of thought--and thus various levels of writing--beyond the literal level; composition teachers want essays to represent higher-order thinking--interpretation, analysis, evaluation, and creativity--and this higher-order thinking demands language use beyond the literal level, a level which often does not rise above the phrase or sentence level.

Some recent handbooks, such as Corder and Ruszkiewicz's Handbook of Current English, published in 1985, ignore coherence errors at the sentence level and instead, focus solely on coherence errors at the paragraph level, either within a paragraph or between paragraphs, as the following examples illustrate:

\section{[1:3a] (focus on intra-paragraph coherence)}

Many people today believe that objectionable movies should be censored by federal or local agencies. The recent emphasis in American films on immorality and violence is outrageous. They are undermining our nation's morals and our prestige abroad, according to many people. There may be some truth here. I agree with the diagnosis, but I cannot accept the cure. 
Censorship poses a greater threat to a democracy, in my opinion.

\section{[1:3b] (focus on intra-paragraph coherence)}

Many people today believe that objectionable movies should be censored by federal or local agencies. These critics have been outraged by the recent emphasis in American films on immorality and violence. such films, according to them, are undermining our nation's morals and our prestige abroad. This may be true. However, although I agree with their diagnosis, I cannot accept their cure. It seems to me that censorship poses a greater threat to a democracy than objectionable entertainment. (Corder \& Ruszkiewicz 464-65)

Due to the changes noted, example "b" possesses

improved coherence. For inter-paragraph coherence, corder

and Ruszkiewicz offer the passage below.

\section{[1:4] (focus on inter-paragraph coherence)}

Putting food into the weightless body has always been a special challenge for NASA. For a while no one was sure if a human could eat normally in zero-g. There were those who worried that when John Glenn made the first American around-the-world space flight he wouldn't be able to swallow his food in weightlessness and would choke to death. Once Glenn returned to earth, his stomach full, his throat clear, extraterrestrial meal planning began in earnest. space meals have progressed from such items as gelatin-coated coconut cubes and peanut cubes to complete heat-and-serve meals on board skylab and the space shuttle.

Space meals are not prepared so much as assembled. All the food is precooked and is either canned, dehydrated, or packed in aluminum-backed plastic envelopes called flex pouches. Because it's impossible to pour water in zero gravity (it congeals into silvery balls that drift around in a spacecraft), dehydrated food is revived by squirting water through a needle into the sealed plastic pouches. Each pouch has a flexible plastic top that lets the cook knead the water into the dried food. Liquids are drunk through a straw with a clamp attached to keep the straw pinched shut when not 
in use. All are in containers shaped to fit neatly into a compartmentalized and magnetized food tray, where they are anchored in place by Velcro tape.

Weightlessness affects not only how food is packaged, but also what kind of food is inside. Even without gravity, it is possible to eat some foods off an open plate with a fork or spoon. Meals with sauces or gravies work especially well because they tend to stick to the plate and not float away. The skylab astronauts, who tested out many space meals, found some were disasters. In one report to Earth, the first crew crossed chili off their eating schedule. Every time they opened a container of it, there was an explosion of food: "Great gobbets of chili go flying all over; it's bad news."--Douglas Colligan, "The Light Stuff" (Corder \& Ruszkiewicz 465-66)

Corder and Ruszkiewicz, as do many other handbook authors, choose not to provide a multi-paragraph passage flawed with coherence errors, but they do point out that example [1:4] employs repetition of "key words" and "synonyms" in order to effect greater coherence (466). Note should be made, however, that inter-paragraph coherence is also effected by other key elements of coherence, such as reference, substitution, ellipsis, and conjunction, and these elements need to be addressed.

Despite the uneven treatment given the notion of coherence in the field of composition, it.was one of six criteria used to evaluate freshman compositions in the influential Miami of Ohio study (Kerek, Daiker, \& Morenberg 1111); like ancient rhetoricians such as Aristotle, Horace, and Longinus, modern rhetoricians also believe coherence is the sine qua non of any composition. If this is the case, then how is it that compilers of current handlists of 
rhetoric and composition terminology do not mention or index coherence (e.g., Lanham; Woodson)? How is it that researchers of the past twenty years in composition and rhetoric do not address coherence (e.g., Hillocks)? How is it that bibliographers list coherence as a category with 265 entries but none deals with coherence (e.g., Lindeman)? How is it that college handbooks indiscriminately assign a single proofreading symbol, "coh," to a multitude of errors at the sentence level (dangling modifiers, misplaced modifiers, faulty parallelism, etc.), at the intra-paragraph level, and at the inter-paragraph level (e.g., Hodges \& Whitten; Hairston \& Ruszkiewicz; Corder \& Ruszkiewicz)?

The reasons the notion of coherence has been treated so unevenly while continuing to possess the status of sine quo non are three-fold:

Humans naturally assume that things "make sense"; "making sense" is the "unmarked" condition or quality of language processing. Because coherence is so much a requisite of language processing, humans take it for granted as much as they do the solidity of the ground beneath their feet. Coherence is part-and-parcel of normal speech; humans do not communicate not to be understood, but instead to be understood and to understand. Coherence is assumed not only of speech production, but also of written-language production; however, the notion of coherence in a written 
text is much more involved than the notion of coherence in a spoken utterance, as this study will demonstrate.

Secondly, composition teachers have focused too long on the "surface language" of the text. They read a sentence constructed with a misplaced modifier and pause to wonder just what is meant, but that experience does not justify restricting their treatment of coherence to the sentence level, and often, therefore, to the literal level of language; they must instruct their student writers to go beyond the literal level of language and thought so that the student writers will not only think at the analytic, interpretive, evaluative, and creative levels, but also articulate at these higher levels of thought in globally coherent essays. Composition teachers appropriately mark the incorrect use of therefore in student papers, but they are remiss if they do not encourage student writers to look at the underlying logical relationships of the clauses the student writers are connecting, for that will give the students an increased understanding of how parts of a composition cohere in fundamental, cognitive ways. Composition teachers correctly alert their student writers to the liabilities of sexist language and to the proper form of a business letter, but it is far better to also teach them about the implicit but overarching, powerful, and ubiquitous influence contextual salience exerts in their culture, and thus in their compositions. 
Aristotle defined rhetoric as "the faculty of discovering in the particular case all the available means of persuasion," and clearly, such a definition is a very inclusive one (Aristotle xxxvii); in a personal interview, Jim corder defined rhetoric as "any purposive use of language"; clearly, this definition is another very inclusive one. Whether one subscribes to Aristotle's definition or to Corder's definition or to both, one must agree that the discipline of composition and rhetoric is very inclusive, and that the language one uses and the resources one draws upon in fashioning a coherent text go far beyond the actual language of the text. Composition teachers therefore must not limit themselves, nor their language, to a text-bound view of coherence; they must not place all the burden of coherence on the text's surface language. Instead, as they teach student writers to compose globally coherent texts, they must alert the student writers to the germane aspects of language use which the text's surface language pre-supposes at the cognitive level, instantiates at the literal level, and intimates at the sociological level.

A third reason the notion of coherence has been treated so unevenly while continuing to possess the status of sine qua non is that composition teachers have not followed the lead of linguists, for as linguists developed a keener and deeper insight into what language is and how it works, their 
field grew beyond general or descriptive linguistics to sociolinguistics, psycholinguistics, and neurolinguistics, for example. Teachers of composition and rhetoric have not sufficiently availed themselves of this growth in linguistics. No doubt, composition teachers have made great strides in moving from product to the process approach, in reviving the essay to a status on par with literary interpretation, and in achieving acceptance of writing-across-the-curriculum. Such strides have seen the discipline of composition and rhetoric become increasingly interdisciplinary. These gains are real and have been good for both teachers and students alike, but composition teachers have not made similar gains in their understanding of the most necessary quality of a composition--global coherence. Nonetheless, they can make significant gains if they appropriately draw from advances offered them by their many collateral disciplines. They can draw, for example, from the increased understanding provided in psycholinguistics by using the concept of top down processing. As argued above, composition teachers have too long focused primarily on the surface language of student papers, and this has often led them into a bottom up approach to the teaching of writing: sentences first, paragraphs next, then a five-paragraph theme, then a genuine essay. However, by using the concept of top down processing in conjunction with bottom up processing (a dual focus which 
in itself more accurately reflects how humans process language), teachers of composition might significantly improve student writing. Further, by taking into account top down and bottom up aspects of global coherence, composition teachers might also complement recent developments in learning theory which suggest that humans as individuals have different cognitive styles, that some of us begin a composition with "the big picture" and then "flesh it out," while others begin with several small observations and details and then build upon them until a coherent composition emerges.

Composition teachers can also begin to treat the notion of coherence more evenly if they look not just at the surface language of a composition, but beneath it and beyond it. Composition teachers must look beneath the surface language to the underlying cognitive processes that all humans share, and they must look beyond the surface language of the composition to the overarching, powerful, and ubiquitous influence contextual salience exerts in the culture, and thus, in the compositions of students: composition teachers simply cannot allow the surface language of the composition to bear the entire burden of coherence. Lastly, composition teachers can begin to treat the notion of coherence more evenly if they draw more and more from what is offered to them by those in their collateral disciplines, for the study of language, and by 
extension, the study of the global coherence of a composition, subsumes a multitude of disciplines and is not, as once was thought, solely relegated to "the Department of English."

\section{Three Lines of Inquiry}

How best, then, can composition teachers make certain they do not assume that the global coherence of a composition is an a priori condition? How best can composition teachers broaden their focus with regard to the various aspects of global coherence so that they carefully examine not only the surface language of a composition, but also the cognitive relationships which underlie the surface language, as well as the contextually salient aspects which overarch the surface language? Finally, how best can composition teachers utilize appropriate concepts from collateral disciplines?

In order to make certain that they do not assume that the global coherence of a composition is a priori, composition teachers need an approach which is sufficiently complex to remind them constantly that the cohering aspects of a composition cannot be taken for granted, but instead demand active cognitive and linguistic skills. This approach, however, ought not be so complex that composition teachers lose sight of the comprehensive, global nature required of a successful composition. In order to examine 
carefully not only the surface language of a composition, but also the cognitive relationships which underlie the surface language, as well as the contextually salient aspects which overarch the surface language, composition teachers need an approach which assures balanced and consistent attention to all these aspects as they co-function to enable global coherence. In order best to use collateral disciplines, composition teachers need an approach which inherently surveys and filters these disciplines for relevant concepts. Numerous works within and outside the discipline of rhetoric and composition which deal with cohesion, coherence, and related concepts suggest that such an approach consists of three "global categories." These three global categories represent three major perspectives of coherence that, for the purposes of this study, I categorize as the linguistic, the cognitive, and the contextually salient perspectives.

The Linguistic Perspective

The linguistic perspective deals with those aspects of global coherence manifested the most frequently and often the most explicitly in a text; such aspects are manifested through and by a text's own language in words meant to be understood at the literal level. Such cohesive language often consists of frequently used words infrequently associated with coherence, such as the, she, it, so, and do. 
Characteristic of the linguistic perspective is Halliday and Hasan's Cohesion in English, which posits five cohering, "non-structural components of the semantic system" of English: reference, substitution, ellipsis, conjunction, and lexical cohesion (29). Halliday and Hasan argue that these components figure centrally in the coherence of a text.

In treating the following passage from Alice in Wonderland, Halliday and Hasan identify the components of reference, substitution, ellipsis, conjunction, and lexical cohesion as they function to cohere the passage:

The cat only grinned when it saw Alice. "Come, it's pleased so far," thought Alice, and she went on. "Would you tell me, please, which way I ought to go from here?"

"That depends a good deal on where you want to get to," said the cat.

"I don't much care where--" said Alice. the cat.

"Then it doesn't matter which way you go," said

"--so long as I get somewhere" Alice added as an explanation.

"Oh, you're sure to do that," said the Cat, "if you only walk long enough." (in Halliday \& Hasan 30)

Working from the last lines to the first, Halliday and Hasan argue that "do that" SUBSTITUTEs for "get somewhere," which is tied through LEXICAL COHESION to "where you want to get to," which is related also through LEXICAL COHESION to "which way I ought to go." "Oh" serves as a CONJUNCTION for "--so long as I get somewhere" and "you're sure to do that," and "then" also serves as a CONJUNCTION as it coheres "I don't much care where--" to ". . it doesn't matter which way you go." In Alice's second utterance, ELLIPSIS coheres 
"where" with the Cat's second utterance ". . . where you want to get to," and LEXICAL COHESION ties Alice's "care" with the Cat's "want." REFERENCE ties "that" in the Cat's first utterance to Alice's question ". . Which way I ought to go," and, again, REFERENCE ties "it" of Alice's interior monologue to "The cat" in the first line of the passage. Throughout the passage, from its beginning to its end, REPETITION ties "Alice" and "the Cat" into a "cohesive chain" (30).

If, in the illustration on the following page, brackets enclose the words in the passage which cohere through ties and ALL-CAPITALS denote the words which tie (the conjunctions, at least in this passage), and lines of coherence are drawn connecting the elements of each cohesive tie, the manner in which this passage is bound together begins to take shape. The elements of coherence in this or any passage effect lines of coherence which exert a binding and unifying force not only between themselves, but also on much of the content within them or near the lines of coherence. 
[1:5b] [The Cat] only grinned when [it] saw [Alice].

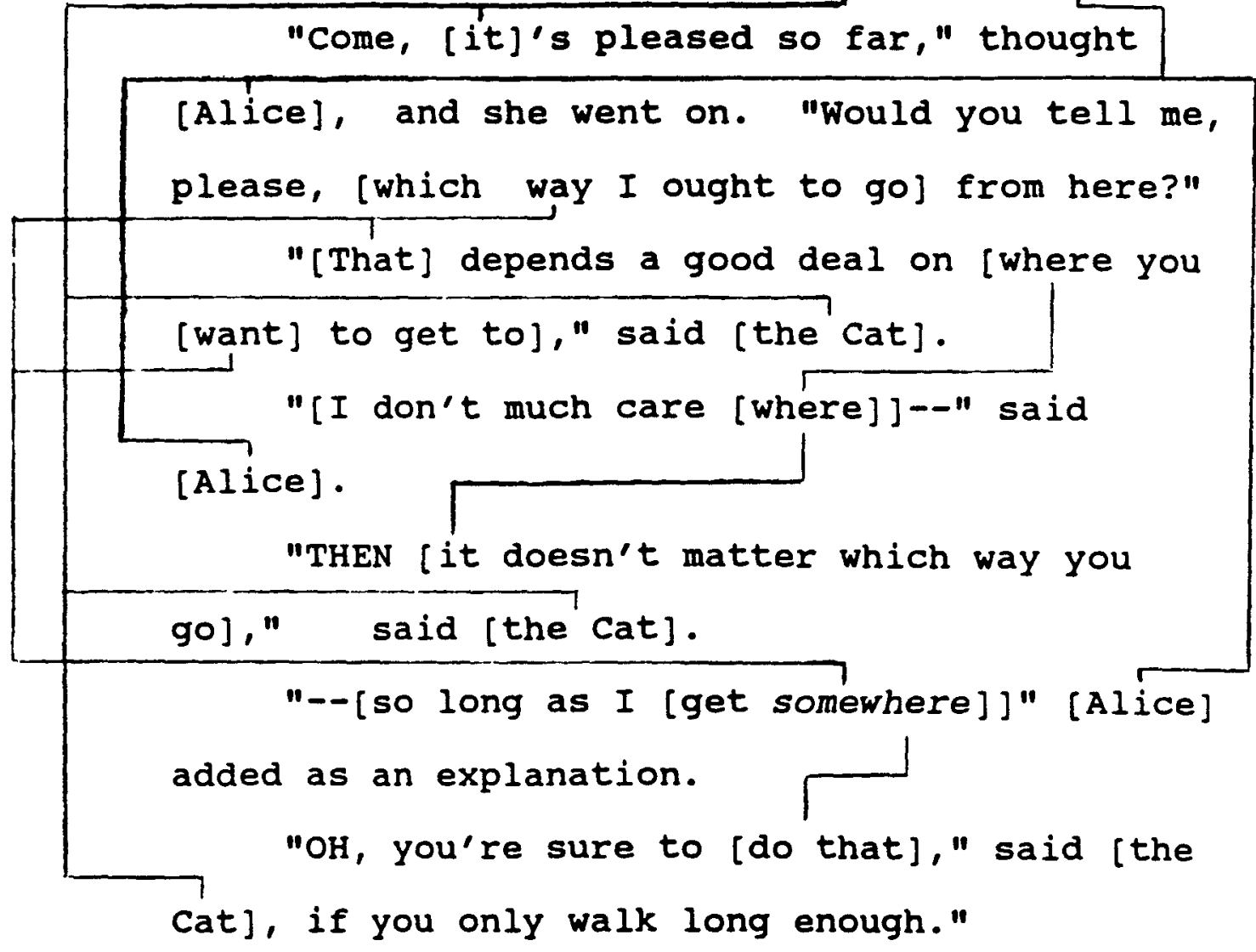

Thus Halliday and Hasan's approach begins to shed light on the linguistic aspects of global coherence, but the analysis of the sample passage also raises questions. For example, pronouns substitute for Alice or the Cat ten times, and it substitutes once for an entire clause ("I don't much care where [I get to].") Are these pronouns, which serve as substitutes for Alice or the cat, and which Halliday and Hasan do not note, a part of the "cohesive chain" represented by the repetition of Alice or the Cat?

One might observe, too, that repetition is not included among Halliday and Hasan's five elements of cohesion, yet it serves a consistent cohesive function throughout the 
passage. Is repetition considered an element of cohesion? If so, is it also "non-structural"? If not, is it "structural"? What are the criteria for determining if a cohesive element is "non-structural" or "structural"? Interestingly, of Halliday and Hasan's five sub-categories of cohesion, (or six, if one counts repetition), only one--conjunction--has words in the text which actually tie, i.e., THEN and $\mathrm{OH}$, while the remaining sub-categories of cohesion do not act as ties, but instead effect coherence by representing a cohesive tie brought about by a structural operation (i.e., substitution, ellipsis, and co-reference), or by a semantic relation (i.e., lexical cohesion, and possibly, repetition.) will this observation hold as one analyzes additional texts? If so, how will this affect the classification of cohesive categories? Yet another question is what do Halliday and Hasan mean by "reference," since reference is a feature of any symbol, word, phrase, or clause? Perhaps more importantly at this juncture in this study of global coherence is, what are the criteria that determine if an element functions in the linguistic, cognitive, or contextually salient global categories? These and other questions are addressed in chapters two, three, and four of this study.

The Cognitive Perspective

Whereas aspects of the linguistic perspective are frequently and most explicitly manifested in a composition, 
the aspects of the second perspective of global coherence, the cognitive perspective, are often manifested in a liminal manner and serve as a threshold at which distinction between the explicit and implicit blurs. However, the essential bridging effect of these aspects is present in every text. The cognitive perspective is exemplified through such concepts as central cognitive processes, natural semantic domains (i.e., those domains which are not socially constructed but which occur in nature, such as a taxonomy in biology), Gestalt, and the relationship between given and new information. One example from the cognitive perspective is the following text of a very familiar routine:

(text \#1) You wake up. You get out of bed. You go to the bathroom. You put on your clothes. You eat. You go to work.

(text \#2) First, you wake up. Then, you get out of bed. Next, you go to the bathroom. After that, you put on your clothes. Then, you eat. Next, you go to work.

(text \#3) You go to the bathroom. You get out of bed. You eat. You wake up. You go to work. You put on your clothes.

(text \#4) First, you go to the bathroom. Then, you get out of bed. Next, you eat. After that, you wake up. Then, you go to work. Next, you put on your clothes.

Members of most cultures or nationalities would find texts \#1 and \#2 globally coherent; it is also quite likely that these same persons would have great difficulty in finding text \#3 or \#4 globally coherent. Text \#2 is globally coherent, and one might posit that such coherence 
is effected by the logical connectors first, then, next, and after that. However, one might argue that text \#1 is also globally coherent, without explicit logical connectors such as first, then, next, and after that. (An additional argument can also be made: the explicit logical connectors in text \#4 do not render the text globally coherent.) How then can text \#1 be judged globally coherent?

one response might be that the actions described in text \#1 are so familiar as to be almost universal, and indeed that is so. Following this line of argument, text \#1 is globally coherent without the explicit logical connectors employed in text \#2 because the actions in text \#1 are virtually universal for all humans. However, the actions in text \#3 are the very same actions as those in text \#1, but text \#3 is not globally coherent. Only the sequence of actions is different, and therein lies the key to the global coherence of text \#1 and text \#2: the SEQUENCE of the actions, i.e., a sequence in time and space that one has come to regard as logical, and not the actions alone, allow for the global coherence of the text. Such a sequence is an example of one of at least fifteen central cognitive processes; other central cognitive processes include but are not limited to contrast, spatializing, comparing, positing causes and/or effects, and classification, and are used to process information, are interconnected, and are sensitive to one's belief system (Fodor 104). Central cognitive 
processes, together with cognitive aspects such as Gestalt and the given/new relationship, form a significant part of the cognitive perspective of global coherence and will be treated in greater detail in chapter three of this study.

The Contextually Salient Perspective

The third perspective of global coherence, that of contextual salience, is usually manifested in the text through such implied but powerful, fundamental, and culturally-related concepts as epistemological frames, central metaphors, sociological models, and warrants. The following example illustrates how contextual salience, or, in this case, subcultural salience, dramatically affects global coherence through the lexicon:

When the tool locates the object, he may name that location to the stalls, saying in an undertone "left bridge" or "right bridge" or "kiss the dog," or whatever instructions may be necessary to inform the stalls, so that they can put the patient into position for the tool to operate. The tool may likewise communicate with the stalls during the operation, giving them instructions such as "roust" or "come through," or "stick," or "stick and split me out" or "turn him for a pit," etc. All tools give the stalls an office or signal when they remove the object. . . . To this researcher "it seems incredible" that the patient does not realize that the language is focused almost exclusively on him. (adapted from Maurer 53-54)

Here is evinced one prominent part of the context, the subculture, implicit and not mentioned in the text, but which makes salient a specific semantic domain and manifests explicitly in the text a specialized vocabulary. Such specialized vocabulary is an essential element of the global 
coherence of this particular text, and the explicit-implicit relationship between specialized vocabulary representing semantic domains and the subculture also holds for entire texts written across the curriculum, whether in business, law, science, technology, or the arts.

The earlier passage from Alice in Wonderland indicates that the linguistic elements of global coherence are the elements used the most frequently and the most explicitly. Similarly, the passage describing the early morning routine and its sequence of familiar actions illustrates how the cognitive elements of global coherence serve bridging or liminal functions, at times explicit and at times implicit. In like manner, the above passage using the argot of pickpockets illustrates that the elements of the contextually salient perspective rely on culturally-related concepts such as epistemological frames, central metaphors, sociological metaphors, and warrants.

Because the contextually salient perspective of global coherence is culturally related, it often seems to be omnipresent and ubiquitous. Paradoxically, the contextually salient perspective is often the most implicit aspect of global coherence, never manifesting itself explicitly or directly, but instead, manifesting itself implicitly in the form of epistemological frames, central metaphors, sociological metaphors, and warrants. Nor is the contextually salient perspective manifested in language 
meant to be understood at the literal level, as in the linguistic and cognitive global categories, but in language meant to be understood at the interpretive level in the form of such key components of a composition as word choice, grammatical structure (voice, nominalizations, etc.), rhetorical pattern of sentences, thesis placement, and prevalence of particular central cognitive processes (often resulting in emphasis on a particular arrangement or pattern of thought). These and other aspects of contextual salience are treated in greater detail in chapter four of this study.

\section{Summary of the Study}

Those scholars operating from a linguistic perspective (e.g., Halliday \& Hasan, Gutwinski, and Markels) seem to emphasize aspects of global coherence which are more explicit in a composition; such aspects might best be studied from the vantage points of descriptive or text linguistics.

Those scholars operating from a cognitive perspective (e.g., Winterowd, Bruner, and Fodor) seem to emphasize aspects liminal in nature, at times manifested explicitly in a text, and at times not, but whose bridging effect is present in every text; such aspects might best be studied from the vantage points of language and cognition, cognitive science, and cognitive psychology. 
Those scholars operating from a perspective of contextual salience (e.g., Hirsch, st. Clair, and Toulmin) seem to emphasize what are often manifestations of very implicit aspects of global coherence; such aspects might best be studied from the vantage points of sociolinguistics, sociology, and ethnology.

The purposes in this study, then, are twofold:

First, I seek to show that virtually all significant aspects of coherence are usefully understood as falling within three global categories: linguistic, cognitive, and contextually salient. This approach achieves several ends:

a) it provides a manageable framework for the analysis of global coherence

b) it redistributes the burden of global coherence from the traditional focus on the surface language of the composition to a tripartite focus which includes not only the surface language of the composition, but also the global factors beneath the surface language and those which function beyond the surface language

c) it draws from the disciplines of psychology and sociolinguistics to validate the cognitive and contextually salient aspects of global coherence

d) elements of global coherence may be identified and assigned to either the linguistic, cognitive, or contextually salient categories; these elements are then located on a continuum in terms of their explicitness or implicitness

e) it offers insight into how a-c above will assist the teacher of composition in further understanding global coherence, and consequently, assist in the teaching of student writers as they wrestle with expressing themselves and the worlds about them in Edited American English

f) a visual metaphor will be offered, illustrating what Longinus alluded to: "the whole texture of the composition" formed by the "mutual 
combination" of "the most important elements" into "what may be called one body" (69).

The second purpose of these study is to raise implications for teaching composition.

This study of global coherence is inherently interdisciplinary. In order to study the comprehensive, systematic connection of constitutive elements of a composition or essay, with a consistent emphasis on both the totality of the text and on the interrelatedness of its constituents, I will draw from classical rhetoric, text linguistics, descriptive linguistics, sociology, anthropology, ethnology, language and cognition, cognitive psychology, and cognitive science.

In addition, such an approach to global coherence may involve a significant amount of re-shuffling of factors traditionally viewed as linguistic or even textual. For example, subordinate conjunctions such as therefore and thus have traditionally been viewed as linguistic, but therefore and thus actually represent one of at least sixteen central cognitive processes, that of positing causes or effects, and from the view of the composition teacher or student, the best use and cohering qualities of words such as therefore or thus might be better grasped if they are treated from the cognitive perspective. Regarding the contextually salient perspective, the re-shuffling of global coherence factors might be seen in the weighing of some extra-textual features on an equal (or more-than-equal) basis when compared to 
textual features. For example, one might weigh the central metaphor dominating a student writer's perspective more than one would weigh his or her choice of prevalent central cognitive processes because the central metaphor might influence not only word choice, but also tone and voice, as well as arrangement.

In an effort to articulate the elements of global coherence and investigate the explicit/implicit dynamic of these elements within a text, I will turn initially to the linguistic perspective, for that has been the traditional perspective from which coherence in the field of composition has been viewed. By reviewing three major works treating cohesion and coherence, I will seek to identify along an explicit-implicit continuum a common set of linguistic elements that fundamentally contributes to the global coherence of a text. These linguistic elements are manifested frequently and quite explicitly through and by a text's own language, in words meant to be understood at the literal level of language. Such words serve not only as content words or function words, but also as ties for coherence. 
Works Cited

Aristotle. Aristotle's Theory of Poetry and Fine Art. 4th ed. Trans. S. H. Butcher. New York: Dover, 1955.

--- The Rhetoric of Aristotle. Trans. Lane Cooper. Englewood Cliffs: Prentice-Hall, 1960.

Bizzell, Patricia, and Bruce Herzberg, eds. The Bedford Bibliography for Teachers of Writing. Boston: Bedford/st. Martin's, 1987.

Cawdrey, Robert. A Table Alphabeticall of Hard English Words (1604). Gainesville: Scholars' Facsimiles \& Reprints, 1966.

coherence. The Compact Edition of the oxford English Dictionary. oxford: oxford U P, 1971.

--. Webster's Third International Dictionary. Ed. P. Gove. Springfield: G \& G Merriam, 1968 .

Corder, Jim W. Personal interview. 10 Oct. 1985.

Corder, Jim W., and John J. Ruszkiewicz. Handbook of Current English. Glenview: Scott, Foresman, 1985.

Davidson, Donald. American Composition and Rhetoric. New York: Scribner's, 1943.

Fuller, Thomas. The Appeal of Injured Innocence. London: W. Godbid, 1659 .

global. Webster's Third New International Dictionary. Ed. P. Gove. Springfield: G \& G Merriam, 1968.

Hairston, Maxine, and John Ruszkiewicz. The Scott, Foresman Handbook for Writers. New York: HarperCollins, 1991.

Halliday, M. A. K., and R. Hasan. Cohesion in English. London: Longman, 1976.

Harbrace College Handbook. John C. Hodges and Mary E. Whitten. New York: HBJ, 1977.

Hillocks, Jr., George. Research on Written Composition. Urbana: ERIC/NCTE, 1986.

Hobbes, Thomas. Decameron Physiologicum: or, Ten Dialogues of Natural Philosophy. no place: W. Crook, 1608. 
Hodges, John C., and Mary E. Whitten. Harbrace College Handbook. New York: HBJ, 1977.

Horace. "Art of Poetry." Critical Theory Since Plato. Ed. Hazard Adams. San Diego: HBJ, 1971. 68-75.

Kerek, Andrew, Donald Daiker, and Max Morenberg. "SentenceCombining and college Composition." Perceptual and Motor Skills 51 (1980): 1059-1157.

Lanham, Richard. A Handlist of Rhetorical Terms. Berkeley: $\mathrm{U}$ of California P, 1969.

Lindeman, Erika, ed. CCCC Bibliography of Composition \& Rhetoric 1987. Carbondale: Southern Illinois U P, 1987 .

Longinus. Longinus on the Sublime. Trans. W. R. Roberts. Cambridge ENG: Cambridge U P, 1935.

Maurer, David W. Whiz Mob. New Haven: College \& University Press, 1964.

Mccrimmon, James. Writing with a Purpose. Boston: Houghton Mifflin, 1974 .

Stewart, Donald. The Versatile Writer. Lexington: D.C. Heath, 1986.

Woodson, Linda. A Handbook of Modern Rhetorical Terms. Urbana: NCTE, 1979. 


\section{CHAPTER II}

\section{THE LINGUISTIC PERSPECTIVE}

This chapter consists of three sections. The first section, an overview of the linguistic perspective, draws upon three major works treating cohesion and coherence in order to identify linguistic elements of global coherence. The second section develops, in effect, a handlist of linguistic elements of global coherence. The third section of the chapter relates these elements to an explicitimplicit continuum as it functions to enable global coherence in compositions and essays.

Overview of the Linguistic Perspective

Several motives drive the investigation of global coherence from a linguistic perspective. One motive is that the structural operations which enable cohesive ties are manifested in the surface language of a text very frequently and very explicitly. Unlike the cohesive ties we will encounter in the cognitive and culturally salient perspectives of global coherence, whose explicit presence in the surface language of a text is often optional or are not even alluded to in the text of a composition, every structural operation which enables a cohesive tie must be explicitly represented in the surface language of a text by 
overt markers (or by the zero marker in the case of elliptical constructions). In short, for every structural operation enabling a cohesive tie in a text, one will find a specific word or group of words in the text whose primary function is not content, but coherence.

Moreover, because markers of these structural operations, along with additional markers of coherence such as subordinators and coordinators at the clause and paragraph levels, appear the most frequently and the most explicitly in the surface language of a text, they are the most easily identified. Given the tendency in this century, at least in America if not in western Europe, towards the analytic rather than the holistic, and the concomitant impetus to quantify data, scholars such as M. A. K. Halliday and Ruquaiya Hasan have focused on the highly frequent and explicit surface-language markers which denote the underlying, cohering structural operations of a text.

Further, it must be added, this focus has been predominantly on cohesive ties at the sentence or clause level as the ties themselves function at the sentence level, within a paragraph, across paragraphs, or throughout an entire text or composition. Such primacy of the sentence level has been disputed and called a fundamental error in compositional theory. Robert de Beaugrande, for example, argues that the sentence is not "the primary unit of speech production and comprehension," and cites several scholars to 
bolster his position (Ohmann; Bever, Lackner, \& Kirk;

Levelt). However, de Beaugrande's argument rests on the premise that if the sentence is not the primary unit in producing speech, then the sentence is also not the primary unit in producing a written text, but this argument does not hold, for writing is not speech written down.

To be sure, both speech and writing use symbols systematically, but they operate in significantly different contents. Normal, unrehearsed speech assumes, among other things, immediate audience response in kind, the complement of prosodic features, and the complement of gestures, all constrained by the working memory's limits of text length and complexity. Consequently, a transcript of a spoken dialog often reveals an uneven progression toward the dialog's goal, with the progression characterized by frequent fits and starts, of numerous stops and returns to the last, mutually understood point the parties of the dialog share. Such a progression is not smooth, and although produced linearly, i.e., through the speech stream, the progression is not linear.

Writing, on the other hand, subsumes all of the above characteristics of speech production as the writer engages in an inner dialog with self or with cohorts in an attempt to produce a written text, but the act of producing a composition transcends the essential and subtended characteristics of speech production because a written 
composition operates in a significantly different context than does speech; the context of the written composition cannot assume immediate audience response, prosodic features, or physical gestures, nor is the working memory as constrained as in speech processing; additionally, the composition, in order to be successful, must exhibit a smooth progression of thought, and do so within the parameters of punctuated linearity.

In order for the composition to do this, certain discrete units, with cognitive boundaries, are necessary, without which punctuated linearity gives way to undifferentiated linearity, to a gigantic run-on of notions and concepts which has only a faint semblance of connectivity and which fails utterly to cohere in a global manner. Thus, the written text must have a basic constituent which enables its linearity to be punctuated consistently according to appropriate cognitive boundaries. This smallest constituent manifests coherence through subject-predicate relations, to use the traditional terms, or through the given-new relationship, to use more recent, cognitive terms. This "smallest" constituent is the clause.

It is both natural and logical for scholars interested in coherence from the linguistic perspective to focus predominantly on cohesive ties at the clause level as the ties themselves function within a sentence, within a paragraph, across paragraphs, or throughout an entire text 
or composition. In point of fact, this "smallest" constituent is incredibly complex, its study having spawned entire theoretical grammars in linguistics, such as transformational-generative grammar, and detailed pedagogical approaches in composition, such as sentence combining.

Despite this focus on the clause, we will not follow the Katz-Fodor argument that discourse, or in our case, a composition or essay, consists basically of an extended and conjoined sentence. Rather, our approach to the elements of global coherence will follow more inclusive arguments such as those advanced by members of the Prague School, Kenneth Pike, William Labov, Dell Hymes, and others: expressed language can be fully understood only when seen as a human action taken within a subsuming context with both explicit and implicit elements contributing to the coherence of the linguistic expression. Or, as stephen witte and Lester Faigley write from a more recent and more rhetorical perspective, "coherence defines those underlying semantic relations that allow a text to be understood" and that "coherence conditions are governed by the writer's purpose, the audience's knowledge and expectations, and the information to be conveyed," among other things (202).

of all the reasons which motivate scholars to investigate global coherence from a linguistic perspective, perhaps the principal reason is a fascination with language, 
and the marvelous, but often taken-for-granted feat of learning a language. Because of the time and complexity required in learning a first language, Nature has endowed humans with an extended neoteny--the most extended of all mammals--to enable them to learn, among other things, this complicated thing called language. Amazingly, humans do so at such a young age that most of them take language for granted and do not even remember learning it. By the age of five or so, humans have acquired a fairly complete grammar, as well as a working vocabulary of several thousand words, all subject to an infinite number of structural combinations in various contexts and for various purposes. Remarkably, also by this early age, these phenomenal feats of language production and comprehension have become automatic within humans, so much so that they think it as natural to use language as it is to eat and breathe. Because it is so natural and automatic, it often seems that to talk is to think, to think is to talk, such that one's inner thoughts and one's "outer speech" are one and the same, but they are not. Ideas, visualizations, and internal cognitive paradigms are not necessarily conceived or "instantiated internally" in linear fashion, yet all speech, and consequently, all writing, must comply with the physiological constraint of linearity.

Linearity accounts for much of the difficulty linguists have had in dealing with semantics and global coherence. 
Traditionally, linguistics was limited to spoken language and to the sentence level, both of which are linear (and written language is even more constrained by linearity than is spoken language); however, semantics and global coherence are not limited to linearity, and trying to treat semantics or global coherence through linearity alone is like trying to define a cube using only the dimension of length without using the dimensions of height and width, or like trying to fully experience a circus while holding one's nose and plugging one's ears. This factor of linearity is the single most distinguishing characteristic between language and cognition.

Fascination with language has also led linguists to investigate the connection between language and thought. One position regarding this connection is that the dynamics of human thought are universal for all humans the world over, yet much of the linguistic aspect of human communications is not universal, but instead, particular for a specific language.

If one follows the line of thinking represented by the speculative grammarians of the 1200s, by the Port Royal grammarians of the 1600s, and by the "Cartesian linguists" of today, one can posit the following key tenets:

1) underlying all languages, i.e., underlying language as sui generis, is a set of cognitive universals which in humans are "hard-wired," $i$. e., physiologically determined; these cognitive universals may be logically prior to linguistic 
universals (this position is articulated in chapter three)

2) because linguistic complexity above the level of the sign develops pari passu with cognitive complexity, linguistic universals have much in common with cognitive universals; thus, these sui generis features of language are best studied from the cognitive perspective of global coherence, not the linguistic perspective

3) differences in languages are principally surface differences, and these differences manifest themselves in particular grammatical features of particular languages; in this study, such features are called sui species features and are best studied from the linguistic perspective of global coherence; hence, the term linguistic refers to these sui species features.

When one distinguishes cognitive universals and linguistic particulars, one sees that language as sui generis is a symbol system which functions in key ways to enable humans to form coherent views of that which is real in their past and present, and of that which may be possible in their future--indeed, this symbol system enables higher-order thinking itself. This symbol system which comprises language as sui generis performs several functions, the foremost of which is reference, for it is through the symbolic function of reference that humans can "establish the temporal and logical priority of empirical reference as the original bond between external fact and conceptual thought"; all other uses of language derive from and depend on this "fundamental semantic link" (Waldron xix) .

The distinction between cognitive universals and linguistic particulars also allows one to note that the 
systematicity of language as a sui species enables humans to categorize linguistic operations peculiar to a particular language, whether the operations are primarily inflections in a language such as Russian, or primarily syntactic in a language such as English. The systematicity of English, an analytic language, allows one to identify structural operations which enable cohesive ties at various levels in a composition: between juxtaposed clauses, across non-juxtaposed clauses, between juxtaposed paragraphs, and across non-juxtaposed paragraphs. Such cohering structural operations in English include substitution, ellipsis, and co-reference.

An approach based on the distinction between cognitive universals and linguistic particulars not only reflects psychological research indicating cell specialization in the cerebral cortex, but for the teacher of composition, this distinction, in combination with the notion of contextually salient features, also re-distributes the burden of communication from what has been the sole traditional carrier, the surface language of the text, to the three global factors represented by the linguistic, cognitive, and contextually salient perspectives. significantly, this approach also concerns itself with the feature of linearity, for the linguistic perspective is the only perspective operating under this constraint, and since it is the most explicit perspective and, indeed, the one through which the 
other two perspectives are related, the composition teacher must be particularly mindful of linearity. Consequently, he or she must also pay especial attention to directionality and how it relates to the nucleus of natural-language logic, a nucleus consisting of reference and logical identity; these concepts are discussed in the context of Halliday and Hasan's work on cohesion.

What follows is a survey of three major works which treat elements of global coherence from a linguistic perspective: M. A. K. Halliday and Ruquaiya Hasan's Cohesion in English, Waldemar Gutwinski's Cohesion in Literary Texts, and Robin Markels' A New Perspective in Cohesion in Expository Paragraphs. The survey ends with the identification of elements of global coherence from the linguistic perspective and their placement along an explicit-implicit continuum.

\section{Halliday and Hasan}

Halliday and Hasan's Cohesion in English is the single most cited work on the topic of cohesion. Scholars such as Waldemar Gutwinski even regard Halliday and Hasan's treatment of cohesion as the ultimate position on textual cohesion, but this position may well be like that of such linguists as Leonard Bloomfield, Charles Fries, and other structuralists who believed the study of language had reached its zenith in the late 1950 s when methods of linguistic analysis enabled the "complete description of all 
linguistic analysis enabled the "complete description of all human languages." Studies in neuro-, psycho-, and sociolinguistics now indicate the fallacy of this position. Nonetheless, Halliday and Hasan's treatment of cohesion in English merits attention, for it deals intricately with the most explicit and most frequently used elements of global coherence.

Halliday and Hasan's method of textual analysis, is, in their words, a "way to offer an insight into what it is that makes a text a text" (328), and to do so they place cohesion within a "description of English," with the sentence as the "highest structural unit in their grammar" (28). Linguistic structures are limited to four "ranks": clause, verbal group, nominal group, and adverbial group. Despite these limits, however, Halliday and Hasan investigate the "linguistic means whereby a text is enabled to function as a single meaningful unit" (29-30). Further, a "text" exhibits "texture" when it "functions as a unity with respect to its environments" (2). According to Halliday and Hasan, texture, or global coherence, is achieved through the mutually complementary relationship of "register" and "cohesion" (23).

Register is "the set of meanings, the configuration of semantic patterns, that are typically drawn upon under the specified conditions, along with the words and structures that are used in the realization of the meanings" (23). 
Two distinctions need to be made at this point, one concerning Halliday and Hasan's meaning of the word reference, the other concerning their dichotomy between the structural and the non-structural. Reference and logical identity form the nucleus of natural-language logic. Reference is the most fundamental property of language, the simple but absolutely essential characteristic enabling the link between linguistic symbol and the thing referred to. However, this fundamental meaning of reference is not what is meant by Halliday and Hasan. Rather, they use the word reference to mean co-reference, i.e., two or more words having the same referent. In this study, the word reference carries its fundamental meaning, and the word co-reference is used wherever Halliday and Hasan have used the word reference.

The distinction between "structural" and "non-structural" cohesion is crucial. For Halliday and Hasan, cohesion is a process in which the relation between two items in a text is enabled, and thus the sub-divisions of cohesion--reference, substitution, ellipsis, conjunction, and lexical cohesion--are also relational, and hence, "non-structural," as opposed to "structural." However, one might argue that Halliday and Hasan operate from a perspective which splits form and meaning by positing this kind of structural/non-structural distinction. The structural category of the semantic system, according to 
Halliday and Hasan, consists of the following components: clause group (theme), verbal group (voice), nominal group (deixis), adverbial group (conjunction), and information unit (information distribution or focus); the non-structural category consists solely of cohesion (reference, substitution, ellipsis, conjunction, and lexical cohesion). However, these five sub-categories of cohesion are structural in nature because co-reference is a form of substitution, as is ellipsis. Indeed, Wolfgang Dressler argues that "conditions triggering explicit and elliptic anaphoric transformations . . are often similar," so similar that he posits, citing various scholars (Lakoff, Green, Dougherty, and steinitz) a universal condition for both explicit and implicit (elliptical) anaphoric transformations: "recoverability or possibility of substitution," and that this is "true for deletion and anaphoric pronouns such as 'he, she, it' or pseudopronominal nouns" (205).

Further, as one will see in chapter three, conjunction is inextricably bound to structure, for it is the role of conjunctions to indicate not only the basic temporal-spatial relationships of thought, but also the complex logical structures of the central cognitive processes.

Lastly, lexical cohesion is, as Halliday and Hasan maintain, non-structural in the sense that the ties enabling lexical cohesion are "associative" in nature (De Saussure 
123, 125-27); these associational ties relate to semantic domains, which are integral to the cognitive and contextually salient perspectives of global coherence addressed later in this study. Lexical cohesion is, however, structural in the sense that the meanings represented by the vocabulary of any semantic domain are wed to forms which, although arbitrary as Ferdinand de saussure noted, are forms nonetheless.

Thus, the structural vs. non-structural dichotomy is an unneeded dichotomy and is founded on the flawed assumption that form (structure) can be separated from meaning. Form and meaning can no more be separated than can language from the development of higher-order thought; the relationship of each pair is pari passu. Halliday and Hasan make a valuable contribution to the linguistic perspective of global coherence by their delineation and examination of such cohering operations as co-reference, substitution, ellipsis, conjunction, and lexical cohesion; this study, however, argues that co-reference and ellipsis are forms of substitution, and that substitution is structural in nature, being achieved through structural operations in English as shown by transformational-generative grammar, and that these structural operations enable cohesive ties which, with few exceptions, are explicitly represented in the surface language of a text by overt markers. (Detailed support of this argument, which refutes Halliday and Hasan's position 
that co-reference, substitution, and ellipsis are non-structural, is found in Appendix I of this study.) Whether co-reference, ellipsis, and substitution are structural or non-structural, correct substitution is essential not only for the sake of variety, but more importantly for logical identity, which, along with symbolic reference, constitutes the nucleus of natural language logic. This nucleus is encompassed by the linguistic, cognitive, and contextually salient perspectives as the visual metaphor in chapter five illustrates.

Moreover, it is argued that conjunction is better examined in the cognitive perspective of global coherence because it is indicative of underlying, basic, and complex cognitive processes. Lastly, it is argued that lexical cohesion subdivides into two categories, natural and synthetic semantic domains, with natural domains better examined from the cognitive perspective because they are products of evolved cognitive processes, and synthetic domains better examined from the contextually salient perspective because they are determined by cultural forces. In sum, though Halliday and Hasan nominally reject any extra-textual considerations of global coherence, their focus on such sui species features of a text's surface language as co-reference, anaphora, cataphora, and ellipsis is apropos this investigation of the linguistic perspective of global coherence. Moreover, Cohesion in English offers 
valuable insight into how structural operations, especially those involving substitution of pro-forms or the zero element, comprise the lion's share of the cohesive elements in the linguistic perspective of global coherence.

\section{Gutwinski}

Waldemar Gutwinski's Cohesion in Literary Texts, published in the same year as Halliday and Hasan's Cohesion in English and drawing from Halliday and Hasan's earlier publications (Halliday 1962, 1964, 1972; Hasan 1964, 1967, 1968), posits a theoretical framework quite similar to that of Halliday and Hasan in terms of cohesive elements. As the title indicates, Gutwinski focuses on works in belles lettres, and he analyzes passages by Ernest Hemingway and Henry James.

One should note at the outset that although Gutwinski touches on research concerning coherence, he believes coherence to be unanalyzable in the linguistic sense because it deals with phenomena which "cannot be treated on a single level of analysis and some of which are not open to linguistic analysis at all" (26). These latter "phenomena" are things such as "gaps in thought," which Gutwinski illustrates with a brief passage from a freshman composition text, Writing with a Purpose, in which the author, James McCrimmon, advises student writers to avoid "gaps in thought" if they wish to write a coherent paragraph. Thus, 
Gutwinski tells us, the term coherence is "carefully avoided" in his study (27).

Gutwinski states that none of the "several competing theories of language organization [the extended standard theory of generative transformational grammar, generative semantics, applicational-generative, tagmemic, systemic, and stratificational grammar] . . . " have "developed a semology or fully-worked out tactics for its upper stratum (lexical hierarchy or lexis)" which "must be seen as an inadequacy if any explicitness is attempted" (23). This view notwithstanding, Gutwinski uses stratificational theory as his theoretical base because "it recognizes and develops several strata, one of which is semology" (25); this semology is defined as a system "behind" grammar that consists of

$$
\begin{aligned}
& \text { meaning contrasts and patterns of sense } \\
& \text { organization } \\
& \text { poorly understood. Yet we suspect that the } \\
& \text { relationship of semology to grammar is much the } \\
& \text { same as that of grammar to phonology. } \\
& \text { (Gleason qtd. in Gutwinski 39) }
\end{aligned}
$$

Gutwinski relates that most of the linguistic phenomena in his study belong to the "grammatic stratum" (sic) of stratificational grammar (25). He thus proceeds to examine "the cohesive relations obtaining between clauses and sentences in some selected literary prose texts," that is, passages from James and Hemingway (26). 
Several "cohesive categories" are offered by Gutwinski (54), the foremost of which is "the method of order" of sentences (55). He states:

The order in which clauses and sentences follow in a text is, then, a cohesive factor which is always present in the text and which in combination with other cohesive factors--and sometimes even alone--indicates what kind of cohesive relations obtain among the sentence and clauses. . . . it [order] will underlie implicitly correlations involving all other cohesive factors studied here. (Gutwinski 56)

Unfortunately, Gutwinski develops nothing further vis-a-vis order and these "implicit correlations." Instead, he focuses on much the same sort of cohesive relations that Halliday and Hasan do. Gutwinski divides cohesive features into two categories, grammatical and lexical. The grammatical category consists of anaphora/cataphora, coordination/subordination, and enation/agnation; the lexical category consists of repetition, occurrence of a synonym or item "formed on same root," and occurrence of an "item from same lexical set (co-occurrence group)" (57). Gutwinski, drawing from Gleason, enlarges the "phoric" category to include not only anaphora and cataphora, but also homophora (reference to general or cultural knowledge, e.g., "the army," "the queen," "the superbowl"), exophora (reference to "a situation outside of language," e.g., using a gesture to supplement one's communication), and paraphora (reference to something in another text, e.g., a line from Shakespeare) (66-68); however, Gutwinski's approach does not 
admit any reference other than anaphora or cataphora, presumably for the same reasons he avoids all use of the word coherence: such aspects, in his approach, are non-linguistic. Although Gutwinski admits only anaphora and cataphora for his approach to cohesion, one can relate all five kinds of "phoric" reference to the notion of linearity, the significant constraint under which the linguistic perspective must operate, but which the cognitive and contextually salient perspectives are free of.

Both Gutwinski and Halliday and Hasan give considerable attention to anaphora and cataphora, with Gutwinski arguing (60-61) that anaphora has traditionally received the most attention of all cohesive features, with that attention initially focused within clauses (Bloomfield), but that later scholars have broadened the scope to include inter-clausal cohesion (Gleason; Halliday \& Hasan; Quirk, Greenbaum, Leech, \& Svartvik). One might add that both anaphora and cataphora adhere to the constraint of linearity and are distinguished one from the other primarily in terms of directionality. Paraphora, too, is constrained by Iinearity, but it is the linearity of another text, and thus it is disallowed per Gutwinski's criteria. One might argue that paraphora is a type of homophora. One can also note that much of these two fundamental kinds of reference is not constrained by linearity, and that they are within the 
bounds of the contextually salient perspective of global coherence.

Again drawing from Gleason, Gutwinski illustrates enation and agnation as grammatical features. Enation, a form of grammatical parallelism, is illustrated by the following nursery rhyme:

$$
\begin{aligned}
& {[2: 71] \text { This little pig went to market }} \\
& \text { This little pig stayed home } \\
& \text { This little pig had roast beef } \\
& \text { This little pig had none. ... }
\end{aligned}
$$

Agnation is "used for relations that are opposite and complementary to enation" (78). The following sentences illustrate agnation:

[2:72] There was nothing left for her but to sell the old family house. This she couldn't do.

This she couldn't do is an agnate structure which serves to cohere the two sentences by reversing the svo word order of sell the old house. However, one might also argue that This, in conjunction with do, are substitutes for sell the old family house, and that This has been fronted through a structural operation akin to the do-fronting transformation in transformational-generative grammar, and that the variation in word order is not as much for purposes of cohesion as for stylistic emphasis. One other example of agnation is the following:

[2:73] James wrote this book. This book was written by James. (78)

Here one has an example of the active-passive transformation. The reason for the alternation between 
structures lies not so much in efforts to cohere a text via structural operations as in the given/new relationship, which, it will be argued in chapter three of this study, is a fundamental part of the cognitive perspective of global coherence.

In sum, Gutwinski offers two main categories, the grammatical and the lexical, whose elements serve as overt markers of cohesive ties and which are explicitly represented in the surface language of a text. The grammatical category consists of anaphora/cataphora, coordination/subordination, and enation/agnation: the lexical category consists of repetition, occurrence of synonyms, and co-occurrence of items from the same lexical group. Yet, as was argued earlier, coordination and subordination might be better treated from the cognitive perspective because of their close relationship to central cognitive processes. Enation, to the extent it is cohesive rather than stylistic, might be better treated from the contextually salient perspective since parallelism is one of several cultural thought patterns that humans use to structure their thought and text (Kaplan). As stated earlier, agnation might be better treated from the cognitive perspective due to its representing the given/new relationship. Those cohesive ties represented by synonyms and items from the same lexical group might best be treated as part of natural or synthetic semantic domains, with the 
former viewed from the cognitive perspective and the latter from the contextually salient perspective. This leaves repetition, anaphora, and cataphora; the latter two result from structural operations as demonstrated by transformational generative grammar, and are forms of substitution differing primarily in directionality. Although Halliday and Hasan also mentioned repetition as a cohesive operation, they did not elaborate on it or assign it to a cohesive category other than to state that it is a type of reiteration (Halliday \& Hasan 278).

The review of Gutwinski and Halliday and Hasan indicates that the basic cohesive categories in the linguistic perspective continue to emanate from the fundamental structural operation of substitution: for Halliday and Hasan, the cohesive categories are co-reference, ellipsis, and substitution, with co-reference and ellipsis being types of substitution, and for Gutwinski, the cohesive categories are anaphora, cataphora, and repetition, with anaphora and cataphora kinds of co-reference, and therefore examples of substitution.

In addition to reinforcing the primacy of substitution as a cohesive tie in the linguistic perspective, Gutwinski expands the notion of reference by drawing on Gleason's work on "phoric" reference. Gutwinski not only treats anaphoric and cataphoric reference in relation to cohesion, but he also treats homophoric, paraphoric, and exophoric reference. 
Although he does not admit the three as cohesive, our approach to global coherence, consisting of not only the linguistic perspective, but also the cognitive and contextually salient perspectives, will admit these latter three types of reference, and hence, they will be explored in the respective chapters of this study. Moreover, Gutwinski's treatment of the various kinds of "phoric" reference enables one to relate each to the notion of linearity, which, as was noted earlier, is a significant constraint for the linguistic perspective, but not for the cognitive nor the contextually salient perspectives.

Markels

Markels' work, A New Perspective on Cohesion in Expository Paragraphs, offers interesting points of commonality and dissimilarity with respect to the works of Gutwinski and of Halliday and Hasan. Where Gutwinski focuses on works of belles lettres and Halliday and Hasan focus on dialog and narrative, as well as belles lettres, Markels focuses on expository writing; where Gutwinski is oriented toward the text as a whole and Halliday and Hasan are oriented towards texts of various lengths exhibiting various degrees of closure, Markels is oriented toward paragraphs. In addition, Markels does not offer an overall framework for analyzing the elements of coherence as do Gutwinski and Halliday and Hasan. In these ways, Markels' 
treatment of the linguistic aspect of global coherence differs markedly from those of Gutwinski and Halliday and Hasan. These significant differences notwithstanding, Markels finds common ground with both Gutwinski and Halliday and Hasan in two key areas: 1) the essential roles of substitution, ellipsis, and [co-]reference in cohering a text; and, 2) the essential and subsuming role of repetition in cohering a text.

Central to Markels' approach is the notion of recurrence; indeed, she argues that "Where a recurrence chain exists, there is cohesion; without a chain, [there is] no cohesion" (14). Although she does not cite Harris, it would seem that Markels' notion of a recurrence chain is quite similar to Harris' "equivalence chain" (6-29); however, Harris explores the use of the equivalence chain through various grammatical structures and lexical domains, while Markels by-and-large restricts her examination of "recurrence chains" to the three structural operations of substitution, ellipsis, and co-reference, all three of which she states are "forms of partial repetition" (17). One should note, though, that although for Markels the notion of recurrence is central to her approach, her view of recurrence goes beyond the notion that it is simply repetition, whether it is manifested through the structural operations of substitution, ellipsis, or co-reference, or whether it is "simply" the repeated use of the same word. 
For Markels, this expanded notion of recurrence comprises

the principal property of linguistic cohesion. Markels illustrates this centrality by using the following two examples:

The opossum has survived in definitely hostile surroundings for seventy million years. The opossum is small; it can easily find a little food, while big animals starve. The individual opossum is not very delicate; it can stand severe punishment. It "plays 'possum" when it gets into trouble. It can go without food for a long time. Many different things are food to an opossum. Traits of the opossum have a high survival value. The opossum is a survivor from the Age of Reptiles. (qtd. in Gorrell \& Laird 125)

$[2: 75]$

The reasons our opossum has survived in definitely hostile surroundings for $70 \mathrm{million}$ years are evident. One is his small size: small animals always find hiding places, they always find a little food, where the big ones starve. Another of its assets was its astounding fecundity; if local catastrophes left only a few survivors, it did not take long to reestablish a thriving population. Also the individual opossum is not exactly delicate: it can stand severe punishment--during which it "plays 'possum" and then scampers away--and it can go without food for a considerable time. Finally, a great many things are "food" to an opossum. Each of these traits has a high survival value, and their combination has presented the United States with a survivor from the Age of Reptiles. (qtd. in Gorrell \& Laird 126)

In the first opossum text, the recurrence chain is established through simple repetition of the word opossum; in the second opossum text, the recurrence chain is established not only by the word opossum, but also through the structural operations of substitution, ellipsis, and co-reference, and such structural operations, Markels 
argues, function in two important ways: 1) they "maintain an unbroken chain of recurrences and thereby establish some degree of cohesion through unity"; and 2) they "subordinate information already known or recoverable by reducing the autonomy of sentences containing that information and forcing the reader back to preceding sentences for the antecedents or other substitutions" (17).

To bolster her argument that repetition is central to cohesion, Markels points out that in various psycholinguistic studies concerned with thematization (Perfetti \& Goldman; Kintsch; Bransford \& Franks; and Crothers), the "shared constant" was repetition, except in the work of crothers, who concedes that lack of repetition "probably explains his negative results" (38). This, Markels states, confirms her hypothesis that "cohesion consists primarily of unity, the presence of a repeated term" (38).

To demonstrate her approach, Markels analyzes two kinds of paragraphs, single-term and multiple-chain. Here one examines her analysis of a single-term paragraph, i.e., a paragraph whose cohesion is established through one recurrence chain, as opposed to a multiple-chain paragraph which may have a dominant recurrence chain and subordinant recurrence chains.

Cohesion in the single-term paragraph occurs when "a term achieves semantic dominance through repetition or 
equivalence" and "appears consistently in the subject or dominant noun phrase position" (45), as in the "basic" paragraph,

The Char-Bar is a bar on High street. The Char-Bar swings. It permits dancing. The bar specializes in foreign beers. The Char-Bar attracts weirdos. It seats 198 people.

as opposed to the following set of sentences which possesses a semantically dominant term, but not one that appears consistently in the subject or dominant noun phrase position:

$[2: 77]$

Alfred likes peaches. Oregon doesn't grow peaches. Peaches contain nitrogen. We have a peach tree in our backyard. No one throws rotten peaches at politicians or ball players. Cut five peaches and sprinkle with sugar. Do you think peach melba would be a good dessert?

Referring to example [2:77], Markels states that "once the repeated term 'peaches' appears in the predicate position, it forfeits the inherently limiting power of the subject position and is itself 'subjected' to at least five other topics: Alfred, Oregon, we, no one, you." Markels continues by observing that "cohesion requires the meshing of both semantic and syntactic information and, at least for some paragraphs - . can be defined operationally" (44).

At this juncture, one certainly does not want to delve into the sticky question concerning the exact nature of semantics and syntax, but one might note that structure, as opposed to syntax alone, occupies a prominent role in this 
study's three-pronged approach to global coherence, and that structure in this study is confined neither to syntax nor to the linguistic perspective. Indeed, it is argued in chapters three and four of this study that structure forms an essential aspect of both the cognitive and contextually salient perspectives of global coherence. Having said this, it can be pointed out that in example [2:77], more than simply placing the word peach in the subject position of each sentence would be required to cohere the collection of sentences into a paragraph, as the "re-structuring" below indicates:

$[2: 78]$

Peaches are a favorite of Alfred's. Peaches don't grow in oregon. A peach tree grows in our backyard. Peaches are not thrown at politicians or ball players. Five peaches are cut and sprinkled with sugar. Peach melba would be a good dessert, don't you think?

Although the "Char-Bar" paragraph [2:76] will never win a prize for style, it at least is cohesive, but even the moving of the word peach to the subject position can not salvage this poor collection of sentences.

Markels' assertion to the contrary, it would seem that a cohesive paragraph subtends more than a meshing of semantics and syntax; it is a meshing of more than these two important elements, and chapters three and four will illuminate, at least in part, other elements which serve to provide a coherent text. Perhaps part of the problem in 
Markels' semantics-syntax argument lies in two of her premises.

The first premise is that English is "position dependent on syntactic information" (45). Markels does not elaborate on what she means by syntactic information, and of course, English is primarily an svo language. However, as the wealth of sentence variety due to variation in word order illustrates, English is not position dependent for syntactic information, as examples [2:77] and [2:78] show.

The second premise is that a transformational analysis can illustrate the semantics-syntax relationship by using the TG concept of dominant sentence node when a collection of sentences employs ellipsis in lieu of term repetition. This premise overlooks the fundamental non-semantic nature of TG sentence trees. As Chomsky and others have repeatedly shown, TG grammar was concerned with syntax, not semantics. Too, a non-sensical sentence tree employing elliptical constructions is easily generated because transformational grammar deals with sentence structure, not sentence sense. It is interesting to note that while Markels stresses that her approach is "[h]eavily grounded in syntactic analysis" (86) and places the burden of cohesion on "the meshing of both semantic and syntactic information" (44), thus confining the role of structure to syntactic structure, she seems to anticipate cognitive and contextually salient elements of global coherence, for she states that "[0]nly 
the concept of an a priori frame" composed of a world view between the communicants can "explain language use" (33), citing research which supports this view (Minsky; Schank \& Abelson; Rommetveit). Such a reference to a priori frames suggests the kind of "hard-wired" central cognitive processes to be explored in chapter three of this study, and the notion of world views, and concomitantly, extra-textual elements, suggests the concepts of central metaphors and epistemological frames which are treated in chapter four of this study. Likewise, Markels seems to anticipate contextually salient elements of global coherence when she reflects on the role subjective interpretation plays whenever a person engages with a text. She quotes stephen Tyler in his The Said and the Unsaid: Mind, Meaning, and Culture:

the "objective and universal character... [of a text and its textuality]. . . can be realized only through the subjectivity of some reader, thus the burden of interpretation." (378)

In sum, Markels does not offer an overall framework which subsumes categories and elements of cohesion as do the authors of the other two major works on cohesion, Gutwinski and Halliday and Hasan; too, Markels' focus is primarily on paragraphs, not on texts comprised of paragraphs. One might also disagree with her premises concerning the role of syntax vis-a-vis cohesion in paragraphs. Finally, Markels does not explore the nature and various manifestations of "phoric" reference as do Gutwinski and Halliday and Hasan. 
Markels does, however, reiterate four aspects of cohesion that both Gutwinski and Halliday and Hasan find central to coherence: repetition, and the structural operations of substitution, ellipsis, and co-reference. Finally, one may observe that she, unlike Gutwinksi and Halliday and Hasan, seems to allow for non-linguistic, i.e., non-textual, elements in the global coherence of a text.

\section{Linguistic Elements of Global Coherence}

As noted earlier, the linguistic perspective deals with those elements of global coherence manifested the most frequently and often the most explicitly in a text; such elements are manifested through and by a text's own language in words meant to be understood at the literal level. As a review of Cohesion in English, Cohesion in Literary Texts, and $A$ New Perspective on Cohesion in Expository Paragraphs indicates, these elements are indeed text-bound, and therefore significantly constrained by linearity, hence the emphases on anaphora, ellipsis, repetition, and cataphora by Halliday and Hasan, Gutwinski, and Markels. Our review of the above-mentioned works also reveals that an additional constraint operates in the linguistic perspective: the constraint of co-reference. Thus, one can make the generalization that linguistic elements of global coherence are meant to be understood at the literal level of language 
and are constrained by the properties of linearity and co-reference.

When one determines to form a cohesive tie, whether immediate, mediated, or remote (cf. Appendix I), one must choose whether the tie will be explicit or have a significant degree of implicitness. If one chooses an explicit tie, three options result: repetition of the referent, an anaphoric pro-form co-referential with the referent, or a cataphoric pro-form co-referential with the referent. If one chooses a tie with a significant degree of implicitness, only one option exists: ellipsis, which, though almost always anaphoric, is largely implicit in nature because of its "zero component."

Thus, linguistic elements of global coherence are represented by four categories: repetition, ellipsis, anaphora, and cataphora. Of these four categories, the latter three are effected in the surface structure of a text through structural operations of the sort illustrated by transformational-generative grammar. The remaining category, repetition, is effected through duplication of the referent. The elements of repetition, i.e., the words used to effect repetition, constitute an open set since it consists of repetition of the referent, and the referent may be represented by any number of constructions or word classes. The elements of ellipsis also constitute an open set since its surface manifestations may be represented by 
any number of constructions and word classes. The elements of anaphora and the elements of cataphora constitute closed sets, those of pro-forms, as indicated in the following handlist.

Handlist of Linguistic Elements of Global Coherence

Repetition (open set)

duplication of the referent itself

Ellipsis (open set)

substitution by the zero element of a portion of a parallel and recoverable form

Anaphora (closed set)

above

The source for the above figures for the deficit is the Congressional office of the Budget.

aforementioned

The aforementioned plat is erroneous in both scale and orientation.

the said

The said will be arraigned on Saturday at noon.

the aforesaid

The aforesaid is not the man we are after.

here

The Versailles Treaty is much too severe, and here the Allied Powers err tragically.

there

The does frolicked in the meadow, and there the youth photographed them. 
then

I opened the door casually; it was then that I realized the room was decorated and all my friends were waiting for me.

this

The hardliners underestimated Mr. Gorbachev, and this was a mistake.

these

The student had split an infinitive and ended a sentence with a preposition. The infuriated teacher shouted "These are the kinds of errors which I will not tolerate!"

that

As the young woman accepted the bouquet of flowers, she smiled and said "That was a gracious gesture on your part."

those

"Give me Socrates, Plato, and Zorba! Those are the Greeks I am most interested in!"

the foregoing

No matter how you argue, the foregoing will need to be notarized.

the preceding

The preceding was unnecessary propaganda. Everyone is already convinced.

the former/the latter

Sonny Liston and Muhammad Ali were two heavyweight champions of the world. The former was an ex-con, and the latter was an extra-good con.

the earlier

The cinema has two matinees on Sundays. The earlier has seats for only one dollar. 
the

A young man stood alone at the highest point of the bridge. The young man was stephen Daedelus.

the first (second, third, ... )

The first was the best.

the last

The last actually scored better because of the softened playing field.

so + adjective/adverb

The theater was absolutely crowded. I did not expect so many people at this performance.

that + adjective/adverb

Rueckert broke the four-minute mark! I had no idea he ran that fast!

such + adjective + noun phrase

I love purple. It is such a royal color.

one

Both students studied hard, but only one passed the exam.

ones

Yes, I know there are all sorts of onions, but only the ones from Valdalia are sweet enough to eat like an apple.

he

John is a solid fellow; he is always honest and considerate.

him

I liked George very much, but I could never understand him.

his

I want to see Jeff's notes; his are easier to read. 
she

My first spanish teacher will always by my favorite, for she is the one I married.

her

Sally dances wonderfully; I could have danced all night with her.

hers

Let me see Cecilia's paintings; hers are always worth buying.

it

Approving the budget will be difficult, but it is vital.

its

Examine the dog's left-rear paw; its webbing has been torn.

they

Mssrs. Reagan and Bush were both traditional

Republicans in that they relied heavily on defense spending .

them

Your sister and your brother will be here for only two more weeks. We must do our best to entertain them.

their

Tolstoy and Dostoevsky have passed on, but their influence continues.

theirs

I have eaten my hamburger, but Sam and Dave have not; theirs is on the stove.

same

Ellen wrote her first novel at age 26, and I did the same. 
identical

The first superchip was manufactured in silicon valley, but an identical one was soon manufactured in Hamburg.

so

Joanna hopes to be home for Christmas. I hope so, too.

do

Democrats want the economy to improve; Republicans and independents do, too.

do it

Jonathan doesn't care how long it takes him to secure a good position. He just wants to do it.

do so

You want me to examine the tires, the carburetor, and the brakes, and I will do so, but please let me eat lunch first.

do that

The police officer asked me to get into his cruiser, but I refused to do that.

do the same

Lyndon Johnson achieved a measure of domestic success, and it is clear that Bill clinton wants do the same.

be

We will be visiting Africa in 1999 for the entire summer, and Mark and Carol also will be.

be it

Paco Sinmiedo will find his name in The Guinness Book of Records, be it next year or the following one.

be so

Mother seems always to be tired, irritable, and sleepy. I don't want her to be so. 
be that

She proposes to continue college after the birth of her twins, be that feasible or not.

likewise

Lafayette was given honorary citizenship, and likewise, churchill.

not

He says that to juggle the accounts to achieve his promotion is the surest and quickest way to advance in the firm, but it is not.

which

I ran seven miles the day I decided to begin my diet, which was not the prudent thing to do.

Cataphora (closed set)

thusly

The Prussian drill instructor yelled "You will do thusly!" Then, he demonstrated an about-face, followed by the clicking of his heels.

thus

"It is thus," intoned the piano teacher, after which his long, slender fingers nimbly scaled the notes.

here

Here is where you are wrong. Inflation will not soar out of control as long as the Federal Reserve maintains tight control of the money supply.

it

It is wonderful to be independent.

this

This is what will happen next. The lioness will actually purr her way out of the $f i x$ she is in!

these

These are the latest photographs of Mars. 
as follows

The criteria are as follows: six foot minimum height, six foot minimum depth, and four foot minimum width.

the following

The successful definition must include the

following: the placing of the term within a class; the distinguishing of the term from other items in the class; an example illustrating the term.

below

Below, you will find the necessary instructions for complete assembly of the rocking horse.

\section{An Explicit-Implicit Continuum}

As noted in the overview of the linguistic perspective, a language is a marvelously complex and prolific system of symbols. This symbol system is so rich and so variegated that it complements the richness and variegation of the human mind in a pari passu relationship, thus enabling humans to achieve levels of thought higher than possible at the level of sign.

The richness and variegation of this symbol system is evident when one considers that in English 26 letters form approximately 1,000,000 words, and of these 1,000,000 words, one can form an infinite number of sentences. It is this unlimited combinatorial nature that one must wrestle with and express oneself through as one attempts to make sense of one's surroundings and life. Fortunately, this burgeoning infinity of language is made manageable through the logic of natural language. At the very nucleus of this logic are the 
semantically primal qualities of symbolic reference and logical identity. Symbolic reference enables the symbol to re-present for the language user the referent, and, as Waldron demonstrates, is not a mundane affair, but one having significant cognitive implications which chapter three will relate to the cognitive elements of global coherence.

symbolic reference is distinguished by polysemy, yet this very characteristic, which elevates sign to symbol, thereby affording to it greater utility, also affords to it greater potential for ambiguity or confusion. This liability is offset, however, by the second nuclear quality of natural language logic, logical identity, for logical identity not only helps one winnow the several meanings a term may have, but it also enables one to view the item with a consistent meaning throughout a text, and it is here that the significance of the linguistic elements of global coherence becomes evident.

If one compares the very small number of anaphoric and cataphoric elements to the million-plus words available in the English language, and, as will be done in chapters three and four, if one compares the essentially explicit nature of these linguistic elements to the relatively implicit nature of the cognitive and contextually salient elements of global coherence, one may rightly be intrigued by their prominence in the overall schema of global coherence; upon analysis, 
one finds that their small number is offset by their high frequency of usage. Further, one finds that their word class, their relatively small number and high frequency, and their mandatory explicitness enable logical identity.

If one holds that symbolic reference is rooted in, but not restricted to, empirical experience, if one follows Wolfgang Dressler and others who posit that semantic deep structure consists solely of noun phrases, and further, that the overwhelming use of symbolic reference is not empirical reference, i.e., referring exclusively to the empirical here-and-now, but instead, that most language use is modal reference, i.e., referring to all situations and circumstances not in the empirical here-and-now (Waldron), one can see that the properties of word class, relatively small number and high frequency, and mandatory explicitness enable the linguistic elements of global coherence to serve an essential role in the cohering of discourse. The dominant word class for the linguistic elements of global coherence is that of pro-forms or their derivatives, even in elliptical constructions (e.g., the possessive pronouns his and hers). These pro-forms are either fuil or truncated noun phrases and represent surface manifestations quite similar to the corresponding noun phrase in semantic deep structure. The small number and high frequency of the linguistic elements of global coherence ease memory load, increase clarity (when used consistently and with a definite 
antecedent), and further reinforce the noun phrase/semantic deep structure property.

The mandatory explicitness of the linguistic elements of global coherence links in a basic way the roots of symbolic reference and empirical reference, the latter of which is explicit by nature. To be sure, pro-forms are used for modal reference as well as for empirical reference, but even when pro-forms are used for modal reference, the condition of mandatory explicitness applies, just as the early users of language had to explicitly re-present their empirically-rooted experience. That is, the early users of language initially used language to refer to the here-and-the-now, and from this "symbolic base," they then developed modal reference. One may even go so far as to speculate that the explicit nature of the linguistic elements of global coherence is, in the evolutionary sense, a remnant of the explicit nature that all early symbolic reference required. Whether or not this speculation will be proven, one can, through analyses of texts such as those by Halliday and Hasan, Gutwinski, and Markels, attest to the predominantly explicit nature of the linguistic elements of global coherence, as the continuum below demonstrates. 
An Explicit-Implicit Continuum

$<------E X P L I C I T---------1--------I M P L I C I T----->$

repetition

anaphora

cataphora

ellipsis

ellipsis

Because of the mandatory explicitness of the linguistic elements of global coherence, all four categories-repetition, anaphora, cataphora, and ellipsis--are located at the explicit end of the continuum, but because ellipsis has an implicit component, it is also located at the implicit end of the continuum. This continuum will be revised and expanded as chapters three and four explore the explicit and implicit nature of the cohering elements treated in the cognitive and contextually salient perspectives of global coherence. 
Works cited

Bever, Thomas, James Lackner, and Richard Kirk. "The Underlying structures of Sentences are the Primary Units of Immediate Speech Perception." Perception and Psychophysics 5 (1969): 225-34.

Bloomfield, Leonard. Language. NY: Holt, Rinehart, \& Winston, 1933.

Beaugrande, Robert de. Text Production: Toward A Science of Composition. Norwood: Ablex, 1984.

---. Text, Discourse, and Process: Toward a Multidisciplinary Science of Texts. Norwood: Ablex, 1980.

Bransford, John, Richard Barclay, and Jeffrey Franks. "Sentence Memory: A Constructive versus an Interpretive Approach." Cognitive Psychology 3 (1972): 193-209.

Bransford, John, and Jeffrey Franks. "Abstraction of Linguistic Ideas." Cognitive Psychology 2 (1971): $331-50$.

Dougherty, Ray C. "An Interpretive Theory of Pronominal Reference." FOL 5 (1969): 488-519.

Dressler, Wolfgang U. "Morphology." Handbook of Discourse Analysis. Vol. 2. Ed. Teun A. van Dijk. London: Academic, 1985. 77-86.

---. "Towards a Semantic Deep structure of Discourse Grammar." Papers from the Sixth Regional Meeting of the Chicago Linguistics Society. Chicago: University of Chicago Department of Linguistics, 1970.

Gleason, H. A. Linguistics and English Grammar. New York: Holt, Rinehart, \& Winston, 1965.

Green, Georgia M. "On Too and Either, and Not Just Too and Either Either." Papers from the 4 th Regional Meeting. Chicago Linguistic Society, 1968.

Gutwinski, Waldemar. Cohesion in Literary Texts: A study of Some Grammatical and Lexical Features of English Discourse. The Hague: Mouton, 1976.

Hairston, Maxine, and John Ruszkiewicz. The Scott, Foresman Handbook for Writers. New York: HarperCollins, 1991.

Halliday, M. A. K., and R. Hasan. Cohesion in English. London: Longman, 1976. 
---. "Categories of the Theory of Grammar." Word 17 (1961): 241-92.

---. "Descriptive Linguistics in Literary studies." English Studies Today, Third Series. Ed. G. I. Duthie. Edinburgh: University Press, 1962. 56-59.

--. "The Linguistic study of Literary Texts." Proceedings of the Ninth International Congress of Linguists. Ed. Horace G. Lunt. The Hague: Mouton, 1964. 302-07.

--- "Linguistic Function and Literary style: An Inquiry into the Language of William Golding's The Inheritors." Literary style: A Symposium. Ed. Seymour Chatman. London: oxford U P, 1971. 330-365.

Harbrace College Handbook. John C. Hodges and Mary E. Whitten. New York: HBJ, 1977.

Harris, Zellig. "Discourse Analysis." Language 28 (1952): $1-30$.

Hasan, Ruquaia. "A Linguistic study of Contrasting Features in the style of Two Contemporary English Prose Writers." Diss. University of Edinburgh, 1964.

---. "Linguistics and the study of Literary Texts." Etudes de Linguistique Appliquee 5 (1967): 106-21.

---. "Grammatical Cohesion in Spoken and Written English: Part One" (Paper No. 7) Programme in Linguistics and English Teaching. London: Longmans, 1968.

Kaplan, Robert B. The Anatomy of Rhetoric: Prolegomena to a Functional Theory of Rhetoric. Philadelphia: Center for Curriculum Development, 1972.

---. "Cultural Thought Patterns in Inter-cultural Education." Readings on English as a Second Language. Ed. Kenneth Croft. Cambridge MA: Winthrop, 1980. 399-418.

Kintsch, Walter, and Teun A. van Dijk. "Towards a Model of Text Comprehension and Production." Psychological Review 85 (1978): 363-94.

Lakoff, George. "Pronouns and Reference." The Linguistics club. Bloomington IN: Indiana U, 1968.

Levelt, willem. "A Survey of studies in Sentence Perception: 1970-1976." studies in the Perception of 
Language. Eds. Willem Levelt \& Giovanni Flores d'Arcais. NY: Wiley, 1978. 1-74.

Markels, Robin B. "Cohesion Paradigms in Paragraphs." College English 45 (1983): 450-64.

--- A New Perspective on Cohesion in Expository Paragraphs. Carbondale: Southern Illinois U P, 1984.

McCrimmon, James. Writing with a Purpose. Boston: Houghton Mifflin, 1974 .

Minsky, Marvin. "A Framework for Representing Knowledge." The Psychology of Computer Vision. Ed. P. Winston. NY: McGraw, 1975.

Ohmann, Richard. "In Lieu of a New Rhetoric." College English 26 (1964) 17-22.

--- "Generative Grammars and the Concept of Literary style." Word 20 (1964) 423-39.

Quirk, Randolph, Sidney Greenbaum, Geoffrey Leech, and Jan Svartvik. A Grammar of Contemporary English. London: Longman, 1972 .

Rommetveit, R. On Message Structure: A Framework for the study of Language and Communication. NY: Wiley, 1974.

Schank, Roger C., and Robert P. Abelson. Scripts, Plans, Goals, and Understanding. NY: Wiley, 1974 .

Saussure, Ferdinand de. Course in General Linguistics. Trans. Wade Baskin. NY: Philosophical Library, 1959.

Steinitz, Renate. "Adverbial-Syntax." studia Grammatica (1969): 10 .

Waldron, T. P. Principles of Language and Mind. London: Routledge \& Kegan Paul, 1985.

witte, Stephen, and Lester Faigley. "Coherence, Cohesion, and Writing Quality." College composition and Communication 32 (1981): 189-204. 


\section{CHAPTER III \\ THE COGNITIVE PERSPECTIVE}

The absence of works treating global coherence from a cognitive perspective precludes a review of works such as that in chapter two, where the linguistic perspective of global coherence was investigated through the works of Halliday and Hasan, Gutwinski, and Markels. Instead, the cognitive perspective will be approached through the umbrella concept of the given/new relationship, through Gestalt psychology, and through central cognitive processes, with the intention of identifying elements of the cognitive perspective of global coherence and locating these elements on an explicit-implicit continuum.

Overview of the Cognitive Perspective

The word cognition derives from co + gnoscere (Latin) and gignoskein (Greek), meaning to come to know (161). Helpful in the understanding of cognition is the derivation of the related term, cognate: co + gnatus (Latin), to be born; akin to gignere (Latin), to beget (161). One additional term will be helpful in understanding what is meant by the cognitive perspective: cognizance, which means range of apprehension, of becoming aware (161). Thus, when one speaks of cognition, one is speaking of purposeful mental activity, and it is precisely this kind of purposeful 
mental activity a composition teacher seeks to nurture in his or her students as they wrestle with and generate their writing.

In a descriptive sense, cognition may be thought of as unconscious, intuitive, or conscious.

Examples of unconscious cognition are the biochemical threshold and the subconscious. The biochemical threshold deals with the firing of neurons and of the interaction of receptors and synapses, among other neuro-anatomical features. The subconscious deals with aspects such as the id, dreams, repressed thoughts, and pre-intuition.

Intuitive cognition is cognition neither conscious nor unconscious but drawing from and dwelling in both states until the intuition's realization or fruition. It is the "Eureka!" experience which continues to fascinate cognitive scientists and composition teachers alike.

Intuitive cognition may fascinate composition teachers, but it is conscious cognition that teachers of composition are primarily concerned with. Conscious cognition may be subdivided into unattending and attending cognition. Unattending cognition is cognition in relation to learned behavior which has become virtually automatic. Examples of this are cognition accompanying ordinary speech, the act of checking for traffic before crossing a street, or the habitual setting of an alarm clock. 
Attending cognition is cognition that is directed and aware, consciously purposeful (cf. cognizance). Attending cognition may be subdivided in the following manner: 1) a normally unattending cognition made attending due to unusual circumstances: 2) metaprocesses; 3) cogitation. Examples of normally unattending cognition made attending due to unusual circumstances are cognition accompanying the deliberate articulation of an utterance, the crossing of a street with a child for the first several times, or the setting of an alarm at 4:00 a.m. to view Halley's comet. Examples of metaprocesses are thinking about thinking, talking about talking, and so forth. Cogitation, the third subdivision of attending cognition, is the conscious, purposeful use of functional cognitive systems qua functional cognitive systems. Examples are formal problem solving, the composing of discourse (purposeful use of a symbol system), or a 16-year-old's arguing for the purchase of his own car. It is this kind of cognition that humans engage in when they consciously and purposefully use functional cognitive systems qua functional cognitive systems, whether these systems are a symbol system in the form of written language or the central cognitive processes discussed below.

Although the principal focus of the cognitive perspective on global coherence will be central cognitive processes as cohering elements within a cognitive system, two global properties must first be considered, for they to 
varying degrees subtend all central cognitive processes as well as the linguistic elements of global coherence. Those two properties are the given/new relationship and Gestalt.

The Given/New Relationship

Regardless of one's epistemological foundations or leanings, whether one is an objectivist, a Cartesian, a Kantian, or whether one hews to the occident, to the orient, or attempts a synthesis somewhere in between, the given/new relationship is fundamental. Without the given/new relationship, one has no point of orientation (de Beaugrande 184-85): one can only flounder endlessly with no hope of making sense of one's thoughts, one's environment, or one's place in it. A human by nature reasons from given to new. The given is one's "old" information, that which one has already been introduced to or stored, and, along with the "new," is fundamentally embedded in epistemological and logical frameworks such as Toulmin's data/warrant/claim, Piaget's assimilation/accomodation, Kuhn's normal science/crisis/revolutionary science, and Hegel's thesis/antithesis/synthesis. Not only does the given orient a person, but it also serves as one's point of departure for cognitive operations, whether the operation is the predication of a sentence, the completion of a hierarchy of categories, or the formation of the categories themselves. 
In the prior chapter, four categories of elements in the linguistic perspective of global coherence were delineated: repetition, anaphora, ellipsis, and cataphora. All four are subject to the given/new relationship.

Repetition, the duplication of the referent itself, is re-iteration of the given.
$[3: 1]$
(G)
(N)
(G)
(N)
(G)
(N)

He will go home; he will eat; he will sleep.

Cataphora is the reversal of the usual direction of reference: it refers forward from pro-form to referent.
$[3: 2]$
(N)
(N)
(G)
(G)
This is what you need to do. You need to go home.

Anaphora represents the normal direction of reference in English, backward from the pro-form to the referent.
$[3: 3]$
(G)
(N)
(G)
(N)
John is a good swimmer. He swims three miles daily.

Ellipsis is rarely cataphoric and almost always

anaphoric; thus, it, too, is a referring backward from the zero element to the referent, enabled through parallel structure:
$[3: 4]$
(G)
(N)
[G]
(N)
[G]
(N)
$I$ want to go home, [zero] eat, and [zero] sleep.

What is noteworthy is that the linguistic elements of global coherence always represent the given in any particular given/new relationship. This specific property of the linguistic elements helps to explain their mandatory explicitness and their high frequency of occurence in a 
text. Moreover, this relationship to the given illustrates the bond between the relatively few linguistic elements in a text and their maintenance of logical identity in the text. The linguistic elements, by representing the given in a text, ensure a consistent point of reference, thus satisfying what is perhaps the first requisite of coherence. Not only is the given/new relationship prevalent in the linguistic perspective of global coherence as evinced in the above examples, but it is also prevalent in the cognitive perspective as the discussion of central cognitive processes will show.

Gestalt

The second global property to be considered in the cognitive perspective is Gestalt. As observed in chapter one, humans naturally assume things to "make sense"; "making sense" is the "unmarked" condition or quality of language processing. Coherence is part-and-parcel of normal speech; humans do not communicate not to be understood, but rather to be understood and to understand. This observation is as true of written communication as it is of spoken communication; however, the propensity towards coherence in written communication, especially in extended discourse such as an essay, is offset by its inherent complexities. Yet these inherent complexities can themselves be offset, at least partly, if one is aware of natural and powerful 
tendencies in humans which have been studied by Gestalt psychologists.

Gestalt psychologists believe that "organization is basic to all mental activity, that it is unlearned, and that it reflects the way the brain functions" (Gleitman 228). Gestalt may be defined as an "organized whole," a notion clearly akin to the views Aristotle, Horace, and Longinus, as well as contemporary teachers of composition, share regarding the nature of the successful piece of rhetoric. In addition to its focus on the organized whole, Gestalt psychology offers the following concepts which relate closely to the composing process composition teachers emphasize in the classroom: good continuation, closure, and restructuring.

Good continuation is "a powerful organizational factor which will often prevail even when pitted against prior experience" (Gleitman 228-29). An example from nature is the tendency of an observer to view the twigs and branches of a bush as continuations of one another, despite the presence of a praying mantis lodged among the twigs and branches. The observer naturally seeks to view the twigs and branches as continuous parts of the whole bush and quite easily "blends" the slightly discontinuous body of the praying mantis into the body of the bush. Likewise, the composition student, once having completed an outline or rough draft of an essay, will also tend to see a continuity 
among the various parts of the whole outline or rough draft. Such a tendency can impel the writer to write the outline or the draft despite not yet having all the details at his or her disposal, for the writer "sees" enough of the "twigs or branches" of "the bush" to generate continuity, and ultimately, global coherence, for the piece of writing. Or, in other words, good continuation often enables the writer to, as Donald Murray puts it, "glimpse the potential text" (60). Of course, this tendency is two-edged: the student may "see" the continuity when others may not, often due to the outline or rough draft being too "writer-based" and not sufficiently "reader-based" (Flower 19-37).

A second contribution from Gestalt psychology regarding global coherence is the principle of closure, defined as the tendency "to complete figures that have gaps in them" (Gleitman 229). If one sees only a portion of a circle covered by a card, one will believe that the unseen portion, covered by the card, completes the seen portion, thus making a complete circle. Likewise, when one sees an unfinished sentence or a fill-in-the-blank sentence, one has a tendency to finish the sentence or fill in the blanks. Partly filled-in crossword puzzles also draw on this cognitive tendency toward closure, as does a cloze reading test. simililary, when one see a "gap" in a draft, one will feel a tendency to close the gap, to make whole, the draft. The challenge for composition teachers, of course, is to 
instruct the student writers in such a way as for them to "see" the gaps in their drafts so that they will then feel this natural tendency toward closure.

The principle of restructuring is yet another contribution from Gestalt psychology toward an understanding of global coherence, especially when the composing process is viewed as an exercise in problem-solving. Gleitman relates that restructuring "involves a dramatic shift in the way [a] problem is viewed. . . [T]his shift may be very sudden and is then experienced as a flash of insight, a sense of 'aha' . . " (330). A similar sort of dramatic shift or sense of "aha" occurs when, after wrestling with how to structure a particular piece of discourse or how to frame a particular topic, one finally grasps the structure or the conceptual frame. This particular Gestalt principle is closely associated with the processes involved in creative thinking and hence will be prevalent in those composing situations involving reflective or emergent thinking that exploratory writing requires (Hairston \& Ruszkiewicz 11-12) .

Just as the efficient cause was vital to Aristotle's understanding of the nature of knowledge (Selections 205), so too is the property of Gestalt vital to the cognitive perspective of global coherence. As Aristotle's efficient cause explains the driving force involved in change or stability, Gestalt entails a natural and powerful "driving 
force" in humans to relate the part to the whole, and it is this part-to-whole (or whole-to-part) relationship which lies at the crux of this study of global coherence, which was defined at the beginning as "the comprehensive, systematic connection of constitutive elements of a text of logical discourse, with a consistent emphasis on both the totality [the whole] of the text and on the interrelatedness of its constituents [its parts]" (chapter I, p. 2).

\section{Central Cognitive Processes}

Central cognitive processes, along with the given/new relationship and the tendency toward Gestalt, are basic to human thought and form a substantial portion of the cognitive universals all humans share. The linguistic elements of global coherence, i.e., repetition, anaphora, cataphora, and ellipsis, help maintain logical identity, and the given/new relationship provides a point of logical orientation, but central cognitive processes serve dual purposes, for they are both "pathways" along which humans experience outer and inner reality as well as the "nuts and bolts" elements humans use as they respond to the Gestalt impetus and attempt to construct satisfactory part-to-whole and whole-to-part relationships.

Since classical times, rhetoricians have known of Aristotle's topoi, which he viewed as places of the mind and ways of finding something to say (The Rhetoric 154). Ross 
Winterowd uses the concept of a "grammar of coherence" in order to understand better the composing process (828-35). Mary Lawrence, drawing from Jerome Bruner, uses the concept of "structural vocabulary" as a pivot in her approach to composition (5). Randolph Quirk, Sidney Greenbaum, Geoffrey Leech, and Jan Svartvik use the term "logical connecters" to designate numerous logical relationships between clauses (661-76). Rhetorical handbooks use terms such as transitions, modes, thought patterns, and patterns of organization (Bain; Davidson; Hairston \& Ruszkiewicz; Corder \& Ruszkiewicz). These various terms have in common their recognition of central cognitive processes. Each composition theorist above employs in his or her approach central cognitive processes, whether singly when using a process such as cause and effect, antecedent and consequence, or genus and division, or in combination with other central cognitive processes as in the expository or argumentative modes.

Central cognitive processes are unique, for they not only occur at the limen on the explicit-implicit continuum of cohering elements, but they also enable humans to generate knowledge as well as organize it. Consequently, central cognitive processes are vital for the invention and arrangement aspects of the composing process and therefore merit special attention. 
Jerry Fodor, in Modularity of Mind, theorizes about a functional taxonomy of cognition. In his theory, the concept of central systems occupies a key role; the characteristics of these central systems are described below. (A more detailed account of the taxonomy is found in Appendix II.)

not hardwired/unstable: neuroanatomy

"relatively diffuse" (118)

quasi assembled: a larger system composed of simpler systems

informationally unencapsulated: central systems access information from each other and from modules

domain neutral: "cut across cognitive domains" (101)

computationally global: may draw on other central systems or modules to perform operations

sensitive to belief system: during computation, central systems consider an individual's set of beliefs

isotropic: confirmation-relevant facts can be "drawn from anywhere in the field of previously established empirical truths"

Quineian: "the degree of confirmation assigned to any given hypothesis is sensitive to properties of the entire belief system; as it were, the shape of our whole science bears on the epistemic status of each scientific hypothesis" (107)

optional engagement: the operation of a central system is not necessarily mandatory; it can be elective

variable speed: may be very slow or instantaneous 
These central systems may be thought of as central cognitive processes; that is, central cognitive processes are specific central systems which possess distinguishing characteristics of their own while simultaneously possessing all the characteristics detailed above in Fodor's theory.

Further, these central cognitive processes, as stated earlier, not only guide an individual along "pathways" through and by which one experiences and cogitates outer and inner reality, but they also serve as "nuts and bolts" elements in the individual's attempts to form coherent views of that which is real in the past and present, and of that which may be possible in the future.

In the introduction of this study (pp. $7,11-12)$, I asserted the necessity of instructing student writers to go beyond the literal level of language and thought so that they will not only think at the analytic, interpretive, evaluative, and creative levels, but also articulate at these higher levels of thought in globally coherent essays. I argued that writing teachers are remiss if they do not encourage student writers to look at the underlying logical relationships of the clauses they are connecting and the discourse blocks they are constructing, for this knowledge will give them an increased understanding of how parts of a composition cohere in fundamental, cognitive ways. The characteristics of central systems detailed above--inherent in the central cognitive processes listed below--are those 
"fundamental, cognitive ways," and it is the central cognitive processes that enable an individual to think in non-linear ways, yet also enable him or her to attempt to express non-linear thought within the constraints of linear language.

While one's expressions in language are constrained by linearity, one's thinking and mental imagery are not (chapter II, pp. 36-40). A significant feature of central cognitive processes, and to a lesser degree, of the given/new relationship and of Gestalt, is their inherent capacity for enabling non-linear thought. Waldron relates that the leap from sign to symbol is monumental because symbolic reference is itself a multi-faceted cognitive operation (50). When one uses a linguistic symbol, one not only assigns a label to an entity, thus employing a referential function to the symbol, but one also assigns to the symbol a logical identity by which one distinguishes it from other items, thus employing a differential function; as one differentiates between referents, one naturally forms categories; thus, the use of a linguistic symbol is also the beginning of the categorial function, and categorization entails central cognitive processes such as contrast, comparison, classification, and hierarchiazation. Language and higher thought, then, truly develop pari passu, for to use the linguistic symbol is to engage fundamental and 
powerful cognitive systems, and yet without the linguistic symbol, these same cognitive systems would be inexpressible. Thus, the listing below of central cognitive processes as elements in the cognitive perspective of global coherence is also the listing of powerful processes that cut across cognitive domains, processes that are not just inter-connected, but which are isotropic. They are also processes that access long-term and short-term memory, that are engaged at the option of the individual person, and that may be used at a speed dependent on the discretion of the individual.

\section{Cognitive Elements of Global Coherence}

Below are sixteen central cognitive processes listed in a developmental continuum, along with illustrative examples and explicit markers. The developmental continuum is tentative, but it may be seen as a provisional step toward understanding how one central cognitive process is logically prior to another. Jung argues that "differentiation is the essence, the sine qua non of consciousness" (95) . Contrast, then, may be thought of as a human's first cognitive act; it could first occur in the womb when the fetus becomes aware of the me/not me distinction regarding its body and the confining wall of the womb. Such a distinction is used by Edmund Leach in his elaborating the notion of binary coding, a property which, he argues, is common to human 
communication $(62-63)$. Further, if categorizing is defined as grouping by differences or similarities, then both contrasting and comparing must be logically prior to categorizing. Similarly, if hierarchiaizing is seen as an ordering of categories according to levels of subordination or superordination, then contrasting, comparing, and categorizing are logically prior to it. Likewise, analogizing presumes contrasting and comparing, at the very least, because it consists of drawing parallels or similarities between or among dissimilar entities. However, such entities may also be hierarchies themselves, and thus analogizing presumes hierarchiazation, as well as contrast, comparison, and analogy. Synthesizing, defined as the expressing of coherence among seemingly disparate entities or relationships, is listed in the final position because when one synthesizes, one is free to draw on any combination of the other central cognitive processes in order to express such a coherence.

The purpose of the list, then, is not to establish its inclusiveness, but to embrace under a single rubric such concepts as Aristotle's topoi, Winterowd's grammar of coherence, Lawrence's structural vocabulary, Quirk, Greenbaum, Leech, and Svartik's logical connecters, and terms often used in handbooks or within the discipline such as transitions, modes, thought patterns, and patterns of organization. 
[3:5] CONTRASTING: the indicating of differences between entities

implicit rendering:

Thomas Jefferson was a very orderly and temperate man; Samuel Adams was absent-minded and hot-tempered.

explicit rendering:

Thomas Jefferson was a very orderly and temperate man, unlike Samuel Adams, who was absent-minded and hot-tempered.

explicit markers: on the contrary, by comparison, on the one hand.. - on the other hand, by way of contrast, instead, but, although, however, differ from, different from, still, otherwise, even so, nevertheless, still, dissimilarly, less than, more than, faster than (etc.), in contrast, in opposition, on the opposite side, while, admittedly, in reality, of course, actually, true

[3:6] SPATIALIZING: the ordering of items in space

implicit rendering:

none possible

explicit rendering:

Please place the green chair here, the red one there, and the couch in between.

explicit markers: next to, alongside of, in, into, out of, outside of, over, under, underneath, below, above, across, among, around, before, behind, beneath, beside, beyond, off, opposite, round, through, within, north, south, east, west, to the right, to the left, front, middle, rear, side, adjacent midpoint, endpoint, diagonal, edge, parallel, perpendicular, co-planar, overlapping, vertical, horizontal

[3:7] COMPARING: the indicating of similarities between entities 
implicit rendering:

Jefferson believed passionately in freedom of thought and freedom of religion.

Franklin, another "founding father," believed strongly in freedom of thought and freedom of religion.

explicit rendering:

Jefferson believed passionately in freedom of thought and freedom of religion. so, too, did Franklin.

explicit markers: as, just as, similarly, similar to, in the same way, almost the same, at the same rate as, like, alike, likewise, in like manner, correspond to, correspondingly, resemble, resemblance, to be parallel in . . . , to have. . . in common, common features, characteristics, etc.

[3:8] POSITING CAUSE AND EFFECT: the stating of an action or a condition and its result

implicit rendering:

Unfortunately, John went out drinking last night. He drove recklessly. Now, he is in the hospital, paralyzed from the waist down.

explicit rendering:

Unfortunately, John went out drinking last night. Because he did so, he drove recklessly. Now, as a tragic consequence, he is in the hospital, paralyzed from the waist down.

explicit markers: so, so that, so much (so) that, thus, consequently, as a consequence, in consequence, therefore, accordingly, for, for fear (that), for the purpose that, for this reason, as a result, hence, because, because of, owing to, since, due to, being that, in that, in the hope that, seeing that, so much that, inasmuch as, forasmuch as, in view of, with this in mind, with this intention, to the end that, lest, if, even if, only if, unless, in case, provided that, providing that, on (the) 
condition that, in the event that given that, granted (that), granting (that), as long as, so long as, then, if so, in that case, that being the case, under those circumstances, if not, otherwise

[3:9] CATEGORIZING: grouping by similarities or differences implicit rendering:

Apples, oranges, and tangerines contain seeds. Fish, beef, and mutton are meats. explicit rendering:

Apples, oranges, and tangerines are alike in that they all contain seeds. Fish, beef, and mutton are similar in that they all are meats.

explicit markers: as, just as, similarly, similar to, in the same way, almost the same, at the same rate as, like, alike, likewise, in like manner, correspond to, correspondingly, resemble, resemblance, to be parallel in . . . , to have . . . in common, common features, characteristics, etc., on the contrary, instead, by comparison, on the one hand . . . on the other hand, by way of contrast, but, although, however, differ from, different from, still, otherwise, even so, nevertheless, still, dissimilarly, less than, more than, faster than (etc.), in contrast, in opposition, on the opposite side, while, admittedly, in reality, of course, actually, true

[3:10] SPECIFYING: the providing of a detail at a lower level of generalization for an entity at a greater level of generalization

implicit rendering:

Diogenes was a simple man. His only material possessions were his toga and a bowl.

explicit rendering:

Diogenes was a simple man. For example, his only material possessions were his toga and a bow 1 . 
explicit markers: for example, for instance, for one thing, to illustrate, in one instance, in other words, as follows, as proof, let me illustrate, let me cite as proof, in substantiation, to substantiate, as an illustration, in this instance, as an example, in practice, according to statistics, according to statistical evidence, such as, especially, particularly, in particular, notably, by way of example, namely, to be specific, specifically, that is (to say); take . . . , for example; consider. . for example

[3:11] ANALYZING: the stating of component parts

implicit rendering:

none possible

explicit rendering:

Although now regarded by many as a quaint form of transportation, a bicycle consists of several highly-tooled parts, including tires, rims, spokes, a chain, and cables.

explicit markers: consists of, is composed of, divides into, includes, including, have, has, components, parts, aspects, qualities, attributes, characteristics, factors, eras, times, regions, sector, factor, piece, particle, section, member, segment, constituent, element, ingredient, feature, contents

[3:12] INDUCING: the drawing of a conclusion from particulars

implicit rendering:

Holmes turned to Watson. "The chemical tests confirm that Eggert's hands had carried sulphur. Eggert was at the scene of the crime. And he certainly had sufficient motive."

"Eggert is our man!" exclaimed watson. But Holmes only furrowed his brow and said, "Perhaps."

explicit rendering:

Holmes turned to Watson. "The chemical tests confirm that Eggert's hands 
had carried sulphur. Eggert was at the scene of the crime. sufficient motive."

And he certainly had

"Therefore," exclaimed Watson, "Eggert is our man!"

But Holmes only furrowed his brow and said, "Perhaps."

explicit markers: so, thus, consequently, therefore, accordingly, for these reasons, as a result, hence, because, because of, owing to, since, due to, it follows, being that, seeing that, as, inasmuch as, in view of, owing to

[3:13] CHRONOLOGIZING: the ordering of entities according to time

implicit rendering:

He unlocked the door and entered the dark room. He turned on the lights. The room erupted in shouts and huzzahs of celebration.

explicit rendering:

First, he unlocked the door and entered the dark room. Next, he turned on the lights. Then, the room erupted in shouts and huzzahs of celebration.

explicit markers: then, now, nowadays, at the present, when, before, after, while, during, between . . . and . . . , in (month/year), in the (period of the day, e.g., morning, afternoon), on (day of week or date), since.. - later, earlier, formerly every (number) (years, months, days, minutes, etc.), at the turn of the century (decade, etc.), in the first (second, etc.) part of the century (month, week, day, etc.), in the l800s, etc., at birth, in childhood, in infancy, in adolescence, as an adult, in adulthood, in old age, at death, simultaneously, simultaneous with, at the same time as, contemporaneously, co-eval, former, latter, previous, previously, prior to, first, second, etc., in the first place, in the second place, etc., to begin with, to end with, next, subsequently, at last, in conclusion, finally 
[3:14] GENERALIZING: the stating of a principle based upon specific observations

implicit rendering:

Rafe is only seven years old; he did not realize he was plagiarizing Lincoln.

olivia is only three years old; she did not know that it is wrong to take cookies without asking. Children are innocent in things such as these.

explicit rendering:

Rafe is only seven years old; he did not realize he was plagiarizing Lincoln.

olivia is only three years old; she did not know that it is wrong to take cookies without asking. All children are innocent in things such as these.

explicit markers: generally, generally speaking, on the whole, all, every, never, always

[3:15] HIERARCHIAZATION: the classifying of categories

implicit rendering:

none possible

explicit rendering:

American government can be subdivided into four levels: local, county, state, and national. Each of these consists of branches comprised of subordinate departments, bureaus, and ministries.

explicit markers: classified, subdivided, levels, graded, sorted, ranked, arranged, ordered, organized, stratified, bracketed, codified, lower, higher, consists of, is composed of, divides into, includes, including, have, has, components, parts, aspects, qualities, attributes, characteristics, factors, eras, times, regions, sector, factor, piece, particle, section, member, segment, constituent, element, ingredient, feature, contents, each, every, single, respective 
[3:16] DEDUCING: the drawing of a conclusion by reasoning from a generality

implicit rendering:

Gringoes have big feet, pale skin, and light eyes. Hans has big feet, pale skin, and light eyes. Hans is a gringo.

explicit rendering:

All gringoes have big feet, pale skin, and light eyes. Hans has big feet, pale skin, and light eyes. Consequently, Hans is a gringo.

explicit markers: generally, generally speaking, on the whole, all, every, never, always so, so that, so much (so) that, thus, consequently, as a consequence, in consequence, therefore accordingly, for, for fear (that), for the purpose that, for this reason, as a result, hence, because, because of, owing to, since, due to, being that, in that, in the hope that, seeing that, so much that, inasmuch as, forasmuch as, in view of, with this in mind, with this intention, to the end that, lest, if, even if, only if, unless, in case, provided that, providing that, on (the) conditions that, in the event that given that, granted (that), granting (that), as long as, so long as, then, if so, in that case, that being the case, under those circumstances, if not, otherwise

[3:17] ABSTRACTING: the assigning of a quality or an intangible to an entity, often tangible

implicit rendering:

Daily, she sacrifices for the poor. Hourly, she prays for the lost. By the minute, she toils to heal the sick. Mother Theresa is love.

explicit rendering:

Daily, she sacrifices for the poor. Hourly, she prays for the lost. By the minute, she toils to heal the sick. In essence, Mother Theresa is love. 
explicit markers: in essence, essentially, in a word, quintessentially, obviously, clearly, without a doubt, nothing but..., sheer, pure, purely

[3:18] HYPOTHESIZING: the stating of a possible explanation or of a contingency relationship

implicit rendering

none possible:

explicit rendering:

If Jonas Salk were to develop a vaccine for AIDS, he surely would be award-ed another Nobel Prize.

explicit markers: if . . then, if so, had, should, in (that) case, provided that, providing that, on the condition that, in the event that, given that, granted (that), granting (that) as long as, so long as, even if, only if, that being the case, under those circumstances, unless, if not, otherwise; were, would, and other subjunctive renderings

[3:19] ANALOGIZING: the expressing of similarity between or among dissimilar entities or relationships

implicit rendering:

The successful actor can perform on the stage in a variety of roles. The successful person can function well in a number of positions.

explicit rendering:

Just as the successful actor can perform on the stage in a variety of roles, so too can the successful person function well in a number of positions.

explicit markers: analogously, as, just as, similarly, similar to, in the same way, almost the same, like, alike, likewise, in like manner, correspond to, correspondingly, resemble, resemblance, to be parallel in . . . to have. - in common, common features, characteristics, etc. 
[3:20] SYNTHESIZING: this, the paramount central cognitive process, transcends analogy and engages all other central cognitive processes to express coherence among seemingly disparate entities

implicit rendering:

Hydrogen is a plentiful yet explosive gas. Mercury is a shiny and toxic liquid quite sensitive to temperatures. Iron is a hard and somewhat brittle solid which decomposes when exposed to air and water. They are fundamental substances called elements and cannot be decomposed into other substances.

explicit rendering:

Hydrogen is a plentiful yet explosive gas. Mercury is a shiny and toxic liquid quite sensitive to temperature. Iron is a hard and somewhat brittle solid which decomposes when exposed to air and water. However different they may be superficially, all three share a unique characteristic. They are fundamental substances called elements and cannot be decomposed into other substances.

explicit markers: the central cognitive process of synthesis is explicitly rendered using explicit markers from any of the other central cognitive processes

An Explicit-Implicit Continuum

our treatment of the linguistic perspective of global coherence (chapter II, p. 74) resulted in the continuum below:

<-------EXPLICIT-----------------------------IMPLICIT------>

repetition

anaphora

cataphora

ellipsis

ellipsis 
It was noted that because of the mandatory explicitness of the linguistic elements of global coherence, all four categories--repetition, anaphora, cataphora, and ellipsis--are located at the explicit end of the continuum, but because ellipsis has an implicit component, it is also located at the implicit end of the continuum.

It was also noted that the linguistic elements of global coherence have special properties which serve an essential role in the cohering of discourse, and that among these properties are their dominant word form, their small number and high frequency in a text, and their mandatory explicitness.

Just as the linguistic elements have special functions which serve to enable global coherence, so, too, do the cognitive elements of global coherence. Paramount among these functions is parallel distributed processing. This function accounts for the interconnection of the above listed central cognitive processes across domains, thus yielding a property the significance of which is difficult to overestimate: utility. If the linguistic elements of global coherence perform a vital function by maintaining the identity of the given in any particular given/new relationship, the cognitive elements of global coherence enable the writer to consummate the given/new relationship by allowing him or her to bring to the "given" the "new" constituent, or to fashion any logical relationship, be it 
one of contrast, analysis, or analogy. Further, the versatility of central cognitive processes enables an individual to do this at the level of clause, paragraph, essay, or book, at the micro-state or at the macro-state, depending on the degree of chunking. Chapter four will deal with the contextual salience perspective of global coherence and demonstrate that not only do humans use central cognitive processes at various levels, but they also use them in various combinations, depending on their purpose and on specific elements of contextual salience.

Unlike the linguistic elements of global coherence, which always have a mandatory explicit component manifested in the text through and by language expressly for co-referential purposes, the cognitive elements of global coherence are often manifested in a liminal manner and serve as a threshold at which the explicit/implicit distinction blurs, as the examples above illustrate. Consequently, the explicit-implicit continuum, with elements from both the linguistic and cognitive continuums, approximates the following:

$\begin{array}{ll}\text { given/new relationship } & \text { Gestalt } \\ \text { repetition } & \begin{array}{l}\text { central } \\ \text { cognitive } \\ \text { processes }\end{array} \\ \text { cataphora } & \\ \text { ellipsis } & \text { ellipsis }\end{array}$


The central cognitive processes occupy the limen portion of the continuum because of the variable nature of their overt markers; at times, their overt markers are necessary, but often they are optional, depending on the rhetorical situation.

In sum, central cognitive processes are universal to humans, operate freely across all cognitive domains, and process information in a parallel, distributed fashion. Hence, central cognitive processes have great utility for thinking in general, and for the student of writing in particular. Their ability to generate as well as organize thought invests them with a unique value in the composition classroom. 
Works cited

Aristotle. The Rhetoric. Trans. Lane Cooper. Englewood Cliffs NJ: Prentice-Hall, 1960.

---. Aristotle: Selections. Trans. G. Fine and T. Irwin. Indianapolis: Hackett, 1991.

Bain, Alexander. English Composition and Rhetoric. NY: Appleton, 1890.

Beaugrande, Robert de. Text Production. Norwood NJ: Ablex, 1984 .

Bruner, Jerome. Studies in Cognitive Growth. NY: John wiley, 1966.

cognition. Webster's Seventh New Collegiate Dictionary. springfield MA: G \& C Merriam, 1965.

cognizance. Webster's Seventh New Collegiate Dictionary. Springfield MA: G \& C Merriam, 1965.

Corder, Jim, and John Ruszkiewicz. Handbook of Current English. 7th ed. Glenview IL: Scott, Foresman, 1985.

Davidson, Donald. American Composition and Rhetoric. NY: Scribner's, 1943.

Fodor, Jerry. The Modularity of Mind. Cambridge MA: MIT P, 1983 .

Flower, Linda. "Writer-Based Prose: A Cognitive Basis for Problems in Writing." College English 41 (1979): 19-37.

Gleitman, Henry. Psychology. NY: Norton, 1981.

Hairston, Maxine, and John Ruszkiewicz. The Scott, Foresman Handbook for Writers. Glenview IL: Scott, Foresman, 1988.

Hegel, G. The Philosophy of History. Trans. J. Bibree. NY: Dover, 1956.

Jung, Carl. Aspects of the Feminine. Trans. R. F. C. Hull. Princeton NJ: Princeton U P, 1982.

Kuhn, Thomas. The structure of Scientific Revolutions. Chicago: U of Chicago P, 1970. 
Lawrence, Mary. Writing as a Thinking Process. Ann Arbor MI: U Michigan P, 1972 .

Leach, Edmund. Culture and Communication: The Logic by Which symbols are Connected. Cambridge ENG: Cambridge U P, 1976.

Murray, Donald. A Writer Teaches Writing. NY: Holt, Rinehart, Winston, 1968.

Piaget, Jean. Judgment and Reasoning in the Child. NY: Harcourt, Brace, 1928.

Quine, W. V. 0. "Two Dogmas of Empiricism." Necessary Truth. Ed. R. C. Sleigh. Englewood Cliffs NJ: Prentice-Hall, 1972 .

Quirk, Randolph, Sidney Greenbaum, Geoffrey Leech, and Jan Svartvik. A Grammar of Contemporary English. London: Longman, 1972 .

Toulmin, Stephen. The Uses of Argument. Cambridge ENG: Cambridge U P, 1958 .

Waldron, T. P. Principles of Language and Mind. London: Routledge \& Kegan Paul, 1985.

winterowd, Ross. "The Grammar of Coherence." College English 31 (May 1970): 828-35. 


\section{CHAPTER IV}

\section{THE CONTEXTUAL SALIENCE PERSPECTIVE OF GLOBAL COHERENCE}

Most humans strive to make sense of life, to discover a coherence in, if not of, life. History and literature are replete with humans engaged in this quest, from figures of note such as Solomon, laden with riches and satiated with pleasures, who continued to quest for coherence in life as he wrote Ecclesiastes and much of Proverbs, to the "small" characters in Tolstoy's War and Peace and Anna Karenina, and those of Dostoevsky in The Brothers Karamazov, Crime and Punishment, and The Idiot, who from their inauspicious beginnings and endings raise the enduring questions of love and hate, justice and injustice, of faith in and doubt of life itself. Regardless of their station in life, these characters wrestle with and through language in their quest for coherence. Language is indispensable in this quest. As Knoblach and Brannon tell us,

Modern rhetorical theory, beginning as early as the seventeenth century, finds a closer connection between language and thought, discourse and knowledge, than ancient speculation had supposed. Far from serving an optional, ceremonial function, composition--the forming process at the heart of writing--is essentially related to learning, to the individual's personal search for coherence in experience. It is also, as a manifestation of human symbolic capacities, a natural endowment in essence, not a technical skill. 
In this quest for coherence, then, humans use "the natural endowment" of language, whether in life in general or in a composition class in particular.

E. D. Hirsch, Jr., maintains that "the peculiar nature of coherence . . is not an absolute, but a dependent quality" (237). He goes on to argue that

The laws of coherence are variable; they depend upon the nature of the total meaning under consideration. Two meanings ("dark" and "bright," for example) which cohere in one context may not cohere in another. "Dark with excessive bright" makes excellent sense in Paradise Lost, but if a reader found the passage in a textbook on plant pathology, he would assume that he confronted a misprint for "Dark with excessive blight." Coherence depends on the context, and it is helpful to recall our definition of context: it is a sense of the whole meaning, constituted of explicit partial meanings plus a horizon of expectations and probabilities. (1190)

Traditionally, the surface language of a text has been the focus for the analysis of coherence. As the review of college handbooks in the beginning of this study demonstrates, answers to questions of coherence were sought routinely in the surface language of a text (Hodges \& Whitten, McCrimmon, Hairston \& Ruszkiewicz, stewart, Corder \& Ruszkiewicz). In actuality, however, the surface language of a text does not bear all the burden of achieving global coherence, as the implicit nature of some of the central cognitive processes illustrates. Consequently, the scope of this study includes the contextually salient perspective as well as the linguistic and cognitive perspectives. By considering implicit elements as well as explicit ones, one 
more accurately represents how various elements of a text contribute to the global coherence of a composition or essay.

While the linguistic elements of global coherence may be used the most frequently and the most explicitly in the text of a composition or essay, and the central cognitive processes of global coherence serve bridging or liminal functions, at times explicit and at times implicit, elements of the contextually salient perspective are manifested in the text through implied but powerful, fundamental, and culturally-related concepts such as epistemological frames, central metaphors, sociological models, and warrants.

Because the contextually salient perspective of global coherence is culturally related, it often seems to be omnipresent and ubiquitous. Paradoxically, it is often the most implicit aspect of global coherence, seldom manifesting itself explicitly or directly through language meant to be understood at the literal level, as in the linguistic and cognitive global categories. Instead, elements of the contextually salient perspective manifest themselves in language meant to be understood at the interpretive level in the form of word choice, grammatical structure (voice, nominalizations, etc.), rhetorical pattern of sentences, thesis placement, and prevalence of particular central cognitive processes, often resulting in emphasis on a particular arrangement or pattern of thought. 
The following overview of the contextually salient perspective will examine the interrelationships of epistemological frames, central metaphors, sociological models, and warrants as they serve to effect the global coherence of a text.

\section{Overview of the Contextually Salient Perspective}

Epistemology deals with how humans know what they know and what they accept as sensible and logical, and hence, what they view as coherent. A human's epistemological framework, then, subtends and permeates all his or her other logical relationships and operations.

In the West, two main epistemological frameworks have evolved, die Geisteswissenschaften and die Naturwissenschaften (Dilthey). Die Geisteswissenschaften is an inclusive framework which accords equal epistemological status to intangible entities such as thoughts, ideas, abstractions, dreams, and logical relationships, as well as to tangible entities such as those represented by one or more of the five senses of sight, sound, touch, taste, and smell. Die Naturwissenschaften is an exclusive framework which accords greater epistemological status to tangible data, ostensibly accepting as valid only that which has empirical characteristics. Another key distinction made between these two dominant frameworks is that die 
Geisteswissenschaften is essentially retrodictive and die Naturwissenschaften is essentially predictive.

often, this dichotomy has come to be viewed as a mutually exclusive one: a datum must fall under one or the other frameworks in either/or fashion. This dichotomy is evident throughout American culture. Colleges and universities are divided between Arts (die Geisteswissenschaften) and Sciences (die Naturwissenschaften); even among the sciences, some are called "soft science," e.g., anthropology, sociology, and psychology (die Geisteswissenschaften), and others are called "hard science," e.g., biology, physics, and chemistry (die Naturwissenschaften); salaries and prestige are distributed according to this dichotomy, with those working in the Naturwissenschaften often receiving higher pay and greater social status, e.g., the mathematician, the physicist, and the chemist, as opposed to those working in the Geisteswissenschaften, e.g., the anthropologist, the social worker, and the historian. Regrettably, this dichotomy forces students to overemphasize one framework at the expense of the other, or to exclude one altogether except for rudimentary courses in fulfilling general education requirements. Such a dichotomy has another unfortunate consequence: many students erroneously believe they are either "science" students or "arts \& humanities" students, and thus they fail to benefit 
fully from the entire spectrum of knowledge and learning that life and academe have to offer them.

The consequences of epistemological frames are apparent. For example, the seminarian operating from the premises of Naturwissenschaften will likely encounter much difficulty, just as the behavioral psychologist who admits only empirical data will meet with frustration. In effect, the epistemological frame serves as a filter for what may be considered logical. Thus, an epistemological frame influences a person's life in the most fundamental of ways. It determines one's very view of reality and the manner by which one deals with this reality. An epistemological frame, then, determines what is sensible and logical, and thus, what is coherent for an individual.

\section{Central Metaphors}

In Metaphors We Live BY, George Lakoff and Mark Johnson write that metaphors have traditionally been viewed in philosophy and linguistics as "a matter of peripheral interest" (ix). In their book, however, Lakoff and Johnson provide copious linguistic evidence which refutes this view. Indeed, they argue convincingly that "metaphor is pervasive in everyday language and thought" (ix). This study in global coherence follows this same argument. Consequently, metaphor comprises the second element examined in the contextually salient perspective. 
The word metaphor derives from the Greek metapherein, meaning to transfer or bear across (825). In relating metaphor to coherence, meanings of the word bear may be helpful: to support and move, to hold in the mind, to sustain, to disseminate, to lead, to give birth to, to permit growth of, to extend in a direction indicated or implied (115).

Metaphor is defined as a type of one of the central cognitive processes, analogy. Metaphor consists of two pairs of elements; one half of each pair, called the attributant, expresses qualities or characteristics. The remaining half of each pair has a naming function and is called the nominal. These terms are used because they are discipline neutral and functional in nature, as opposed to those common to literary criticism such as tenor, vehicle, and image, which presuppose a theory of tension in treating metaphor (Richards). Instead, the relationship used here emphasizes a mapping between cognitive domains.

Consider the following three metaphorical expressions: A) That boxer is a tiger; B) Hought is pronounced so that it rhymes with bought; C) The world is a stage.

Metaphor A may be thought of as consisting of the following two pairs of elements: elemental pair 1:

animal with great strength \& quickness (attributant) tiger (nominal) 
elemental pair 2:

man with great strength \& quickness (attributant) man (nominal)

Metaphor $\mathrm{A}=>$ That boxer is a tiger.

Metaphor B (Glass, Holyoak \& Santa) may be thought of as consisting of the following two pairs of elements: elemental pair 1:

consonant cluster/known pronunciation (attributant)

elemental pair 2: bought (nominal)

consonant cluster/unknown pronunciation (attributant) hought (nominal)

Metaphor $B=>$ Hought rhymes with bought.

Metaphor $c$ may be thought of as consisting of the following two pairs of elements:

elemental pair 1:

where actors roleplay (attributant) stage (nominal)

elemental pair 2:

where humans function in various roles (attributant) unknown life model (nominal)

Metaphor $\mathrm{c}=>$ The world is a stage.

All metaphors derive from two elemental pairs. Of the four elements (two attributants and two nominals), at least three must be known. of the three known elements, cognitive focus is on the two parallel elements, either attributant:attributant or nominal:nominal. Further, any number of the central cognitive processes subsumed by 
analogy (chapter III, p. 93) can be utilized in order to achieve the metaphor. Hence, the emphasis is on a mapping between cognitive domains rather than a theory of tension. A metaphor may serve as a device for the bridging of linguistic, cognitive, and experiential gaps. Linguistic bridging occurs when one has the thoughts and the commonality of experience, but not the language, due to a deficit in the speaker's idiolect or in the language itself: for example, a speaker of English's resorting to the German word blitzkrieg to describe a battle tactic in the European Theater of World War II. Cognitive bridging occurs when one cannot apprehend meaning despite adequate language and commonality of experience: for example, the use of the hand to explain the concept of base ten in mathematics. Experiential bridging occurs when one cannot apprehend meaning despite adequate language and cognition: for example, an extra-terrestial's borrowing from Earth culture in order to explain to an Earthling a circumstance peculiar to the extra-terrestial's world. A metaphor may also serve as an expressive device, the kind of which is often used in poetry, colorful language, or literature:

That boxer is a tiger!

\section{OI}

or ever the silver cord is loosed, or the golden bowl is broken, or the pitcher is broken at the fountain, or the wheel broken at the cistern;

Then shall the dust return to the earth as it was, 
and the spirit shall return unto God, who gave it. (Ecclesiastes 12:6-7)

A metaphor may also serve as a condensed expression: for example, in answer to the question "What kind of politician was Margaret Thatcher?" one replies "She was a female version of Ronald Reagan, but more cerebral and candid."

Thus, metaphor is a much-used central cognitive process; one often uses a metaphor as one attempts to explain to others or to one's inner self how one aspect of reality relates to another. Weighty expressions such as "life is a journey" or "the world is a stage" and less weighty expressions such as "that boxer is a tiger" or "she's a trip" help one communicate or understand what one thinks or feels. Lakoff and Johnson relate that metaphor is "as much a part of our functioning as our sense of touch" (239). Accordingly, a tendency towards a wide use of metaphor seems second nature, and rarely does one shy from it; rather, more often than not, when a particular metaphor fails, one searches with alacrity for other metaphors that might better convey one's understanding. One might think $\mathrm{x}$ is like $\mathrm{Y}--$ no, like $\mathrm{Z}$ ! No, $\mathrm{X}$ is like $\mathrm{A}$ ! Yes, that's it! $\mathrm{X}$ is A!" But, of the many metaphors humans employ daily and hourly to help them better communicate or understand, they, in a desire to simplify life and their comprehension of it, often employ a metaphor which subsumes all other metaphors, and indeed, permeates their thoughts and emotions and either 
reinforces their instincts or conflicts with them. Such a metaphor may be called a central metaphor.

A central metaphor serves humans in two crucial ways, as guide and as touchstone. A central metaphor serves as guide when it indicates to an individual one's role, and consequently, one's behavior, in life. Just as importantly, a central metaphor also serves as guide when it indicates the role and behavior one comes to expect from fellow humans and from one's environment. A central metaphor serves as touchstone when one returns to it to reassure oneself of one's own weltanschauung and to re-affirm concord with one's epistemological frame. In a sense, it serves as a place in one's consciousness where one can always go in order to sort out the variables and changes of life. Central metaphors, then, are of the utmost importance in life.

Because they serve as shorthand versions of epistemological frames, their number is few, and humans normally use a small, consistent number of them, for they must be reasonably consistent not only with one's epistemological frame, but also with one's belief systems. Indeed, some humans choose to die before they can or will exchange particular central metaphors. Witness the individual who has embraced the central metaphor of chance and uses it as an excuse to continue an addiction to alcohol or to gambling, or witness the individual who has taken for one's own the central metaphor of games and competes 
according to an agreed-upon set of rules for designated prizes (Brown). Thus, central metaphors are quite powerful and exert great influence on individuals.

It was noted in chapter three (p. 89) that central cognitive processes are isotropic and sensitive to belief systems. Central metaphors are particularly isotropic and sensitive to belief systems. Whenever one seeks to apply or validate a specific central metaphor, one is utilizing the central cognitive process of analogy, and due to its position in the hierarchy of all central cognitive processes, one may employ any of the subsumed central cognitive processes (only the central cognitive process of synthesis is not subsumed by analogy). Further, because of the isotropic quality of central cognitive processes, one can draw from "anywhere in the field of previously established empirical truths" to confirm that a configuration of data is indeed what it seems to be (Fodor 105). For example, in order for one to use the central cognitive process of classification to determine that the object that a set of adjectives is describing is an animate male human, one may draw from any of one's empirical experiences to confirm that the object is actually an animate male human.

But central cognitive processes, and by extension, central metaphors, are not limited to empirical data, for, as Fodor argues, they are also sensitive to one's belief 
system. For example, if an individual were not acquainted with or did not accept transvestism and saw a male dressed in hose, high heels, dress, make-up, and a wig, that individual might not classify the male as a male regardless of the adjectives indicating that the person was indeed an animate male human. Not only are individual central cognitive processes sensitive to one's belief system in the intra-cultural sense, but also in the cross-cultural sense. While the dominant thought pattern in English is linear, that in semitic languages is often parallel, and in many of the oriental languages, the dominant thought pattern is that of a spiral (Kaplan 410). Thus, the belief systems of the individual and of the individual's culture influence significantly what and how data are classified, hypothesized, abstracted, and analogized, for example, as well as whether the dominant arrangement in a text is of one particular order or another. If the data are not processed or arranged in accordance with the belief system, the result is judged incongruous with one's central metaphor, and quite possibly, incoherent.

Accordingly, Lakoff argues that metaphors go beyond the traditional view of figures of speech (tropes): metaphors are "figures of thought" (215). This view more accurately reflects the variety of elements and immense scope of central metaphors; however, it also reveals the complexity of central metaphors for the following reasons: 
1) All thought ultimately derives from time and space relations, and it is arguable that time is a function of space, or at the very least, is dependent upon space for its conceptualization (Jones 77-83).

2) Central metaphors are ubiquitous: they exist in unconscious as well as conscious cognition, and they may be instrumental in certain instances of intuition. Further, central metaphors, because they are metaphors, are a type of analogy, the central cognitive process which subsumes all other central cognitive processes except that of synthesis, and as a central cognitive process, is, among other characteristics, domain neutral and isotropic.

3) Metaphors, due to their position in the hierarchy of central cognitive processes, are isotropic to a very great degree, and the greater the isotropism, the less one can comprehend the process (Fodor 106), and this property is intensified in a central metaphor because of its scope.

Metaphor, then, is limited only by space and its relationship in the hierarchy of central cognitive processes: consequently, central metaphors overarch one's thought processes and exert tremendous power and influence in one's perception of how various elements of perceived reality interrelate; indeed, central metaphors determine these very relationships.

The following are categories of some of the more dominant occidental central metaphors: the metaphor of growth, which has its formal roots in classical Greek thought and is seen in various guises, for example, as process or progress; the metaphor of drama, in which life is viewed as a stage and members of society perform various roles; the metaphor of chance, in which life is likened to a 
game of chance or fortune; the metaphor of games, in which members of society compete according to an agreed-upon set of rules for designated prizes (Brown). Accordingly, central metaphors subtend virtually all the aspects of one's consciousness and thus, one's notion of what fits with what, what makes sense, what does not, and, significantly, what serves to effect coherence and what does not.

Because of their powerful and deep influence, central metaphors lead to the formulation of sociological models, through and by which humans conduct their lives. All the sociological models sketched below "assume that human beings negotiate their way through life in quest for meaning" (st. Clair, "Language" 225), and that language is the medium of symbolic representation which humans use for the construction or understanding of social reality and the maintenance of cultural values. Further, language is the medium of symbolic representation for an individual, group, or society as problems, topics, or questions of self and society are explored in a quest for coherence.

Within each of the four models of sociology outlined below, language is used in various ways as an individual engages in interpretive, analytical, critical, and creative thought, going beyond the level of signs, of surface impressions, and surface thinking. In so doing, the individual consciously and purposively uses language as a symbol system in an attempt to form or fit his developing 
knowledge into a coherent whole. This treatment of central metaphors and sociological models does not imply that an individual will employ a fixed number of central metaphors and a particular sociological model and only those metaphors and model, although this may be the case in some instances. Rather, this treatment seeks to reveal how individuals may use various central metaphors and sociological models, including but not limited to those mentioned below. Some individuals may vary operative central metaphors and sociological models as circumstances dictate.

Each of the two larger divisions of sociological models--symbolic interactionism and phenomenology--embodies the notion of social construction. Symbolic interactionism embodies the concept of a socially constructed world; phenomenology embodies the construction of social consciousness. Whether the sociological model is one of symbolic interactionism or of phenomenology, it may be subtended by a single central metaphor or a small number of central metaphors which act as a core of ad hoc epistemological frames which help an individual negotiate his or her way through life in some sort of coherent manner. For example, if one embraces the central metaphor that "all the world is a stage" and one has roles in which humans should perform, one very well may operate within the dramaturgical model; on the other hand, if one embraces the central metaphor that life is a jungle and "survival of the 
fittest" is the rule, then one may operate within the ethnomethodological model. Likewise, if one accepts the central metaphor of "the Establishment," one may operate within the labeling model, or, if one subscribes, perhaps by default, to the central metaphor of fate, then one may operate within the existential model. (For a similar set of relationships, but based on linguistic models, see Lakoff and Johnson concerning "experiential gestalts," [77-86].)

The following schemata seek to highlight contrasts and similarities between the dramaturgical and labelling theory models of sociology, which are subtypes of symbolic interactionism, and the existential and ethnomethodological models of sociology, which are subtypes of phenomenology (St. Clair, "Language").

\section{Dramaturgical Model}

a. Social roles are created.

b. Individual perform in roles and use scripts.

c. Members are both audience and critic.

d. Stage fright can be enhanced.

Labelling Model

a. People share a common world of symbolism.

b. Members are taught views of the world.

c. Such teaching establishes norms.

d. Norms enable an insider/outsider distinction. 


\section{Existential Model}

a. The world is without meaning.

b. Belief systems are arbitrary.

c. The world is full of alienation and insecurity.

d. Conflict and negotiation are the norm.

Ethnomethodological

a. Behavior is justified; excuses are explained.

b. Face games protect the member's identity.

c. Relationship games for impression management.

d. Members struggle for establishment of power.

e. An inherent "right to control others" exists.

f. Members have a need to re-affirm self-esteem.

Not only do central metaphors determine in large part one's sociological models and how and what one views as coherent, but they also determine significant parts of one's vocabulary. St. Clair argues that "language is never neutral" (Social Metaphor, 41), and this lack of neutrality is proven when one examines one's lexicon, for it can quickly indicate the operational central metaphor and sociological model. For example, one who is using the central metaphor of chance will likely include in his or her lexicon many of the following expressions:

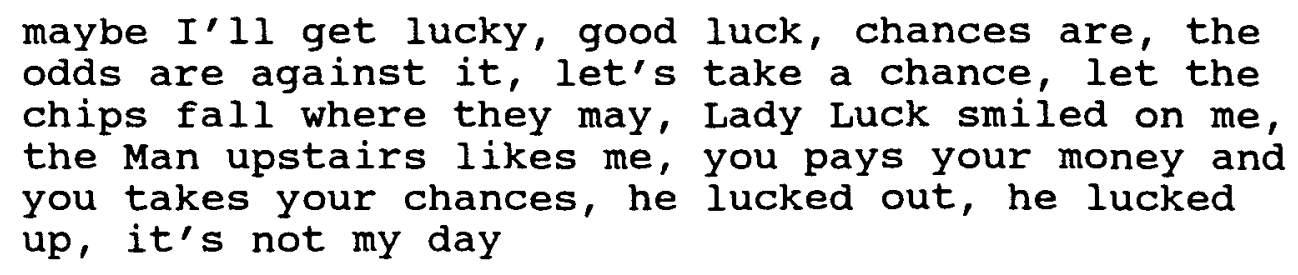

Or, someone who is using the central metaphor of machine 
might have a lexicon which includes the following expressions:

he's wired too tight, learn the nuts and bolts of it, get cranked up, get in gear, stay in gear, can't get out of low gear, missed a gear, in high gear, hit the brakes, a little rusty, in sync, ginning right along

\section{Warrants}

While one does not wear a lapel button announcing to the world which central metaphor one is employing or which epistemological framework one is operating within, both are indicated implicitly in a multitude of ways, such as through body language, lexicon, and prosodic features of spoken language. From the beginning, this study has emphasized the explicit-implicit dynamic that involves the various elements of global coherence. This part of the study examines an element of global coherence that is a form of tacit knowledge and which is integral to the very notion of rhetoric. In classical rhetoric, this form of tacit knowledge was exemplified in the enthymeme, a truncated form of syllogism with one of the premises implied, and is, as Corbett puts it, "the instrument of deductive reasoning peculiar to the art of rhetoric" (74). But the minor or major premise of a syllogistic argument is not all that is implicit in the successful essay or composition.

When one composes an essay, one does not normally state one's epistemological framework, nor the central metaphors 
one lives by, although it is perfectly possible to do so. Likewise, one does not normally explain the sociological model one is operating within. of course, one could inform one's audience that one is a strict empiricist who believes that life is best lived under the law of fang and claw (though this connection is not a necessary one), and that one role-plays and engages in the manipulation of symbols, both linguistic and otherwise, in an effort to "come out on top" in this "civil" contest of life in which only the fittest survive. And of course, one might inform one's audience of one's epistemological framework, choice of central metaphors, and sociological model in a genuine effort to establish rapport, but normally, all of this and much more is implied when one produces an essay or composition, and this tacit knowledge, essential for successful communication between the writer and the reader, may be captured in a single concept: warrants.

In his The Uses of Argument, Stephen E. Toulmin argues against traditional symbolic logic as the truest form of argument. He raises the following questions, questions which bear directly on the notion of contextual salience:

What things about the modes in which we assess arguments, the standards by reference to which we assess them and the manner in which we qualify our conclusions about them, are the same regardless of field (field-invariant), and which of them vary as we move from arguments in one field to arguments in another (field-dependent)? How far, for instance, can one compare the standards of argument relevant in a court of law with those relevant to a mathematical proof or a 
prediction about the composition of a tennis team? (11)

What Toulmin is addressing here when he distinguishes between "field-invariant" and "field-dependent" is the notion of context, specifically, the notion of implied context or background knowledge which the writer can safely assume forms an implicit "bridge" between him or her and the audience. The "standards of argument" may well differ from a court of law to a mathematical proof to predictions of who will and who will not make the tennis team. The standards will vary because the context varies. Indeed, even within argument types, e.g., within the field of law, the standards will vary, as tax lawyers learn very quickly when they seek to become trial lawyers. Thus, the notion of context is pivotal in the coherent argument, as it is in the coherent essay or composition.

Significantly, much of what is contextually salient in a rhetorical situation is implicit. In his model of argumentation, Toulmin calls the implicit part of the background information which forms an implicit bridge between the rhetor and the audience the warrant. It might also be thought of as the implicit and necessary part of a writer's register.

The concept of warrants in rhetoric entails many factors. When one considers writing in various disciplines, one notes that what is assumed for each discipline includes epistemological frame, arrangement, and lexicon. The writer 
of the scientific paper may be wed to empiricism for his or her epistemological frame. Also, he or she may follow a specified arrangement such as observations, hypothesis, hypothesis testing, results, and conclusions, as well as be expected to employ a lexicon specific to the field. Moreover, an "objective" tone will be assumed, and the use of passive voice will be acceptable and perhaps encouraged. In like manner, the writer of the literary essay will most likely operate unconstrained by empiricism, have much more freedom of arrangement, but also be expected to use a lexicon specific to literary criticism. The "subjective" tone may be quite acceptable, even encouraged for the interpretive portion of the paper, and passive voice will, in all likelihood, be discouraged.

Warrants, then, may vary from discipline to discipline, and when one writes in specific disciplines, one must acquaint oneself with the discipline's particular warrants and respect their bounds. If one uses too much warrant, i.e., if one assumes too much, one risks incoherence; if one uses too little warrant, i.e., if one assumes too little, one risks tedious repetition, much as one would if one were to avoid the use of pronouns and elect instead to name the proper noun at its every reference. In this latter case, warrants, in a sense, serve a shorthand function paralleling that of the pronoun in the linguistic perspective of global coherence. 
Moreover, and equally important, the appropriate warrant enables one physician to pick up a journal and read with confidence and efficiency an article written by another physician, or a biologist to read with confidence and efficiency an article written by another biologist, or a social worker to read with confidence and efficiency an article written by another social worker. Warrants are determined by a "match" at various levels of rhetoric: from a narrow match for writing done within particular disciplines by members of the discipline for members of the discipline, to a broad match when one writes for members of what Perelman and olbrechts-Tyteca call the "universal audience" (30-35). Once the warrant has been established, then such rhetorical features as arrangement, lexicon, and tone follow by mutual assent between writer and audience.

\section{Contextually Salient Elements of Global Coherence}

The contextually salient perspective of global coherence is culturally related; thus, it often seems to be omnipresent and ubiquitous. However, it is often the most implicit aspect of global coherence. The contextually salient perspective seldom manifests itself explicitly or directly through language meant to be understood at the literal level, as in the linguistic and cognitive perspectives, but rather in language meant to be understood at the interpretive level in the form of such key components 
of a composition as lexicon, grammatical structure (e.g., voice and nominalizations, etc.), rhetorical pattern of sentences (e.g., balanced, loose, or periodic), thesis placement, and prevalence of particular central cognitive processes (often resulting in emphasis on a particular arrangement or pattern of thought).

What follows is a summary listing of contextually salient elements of global coherence. Just as the listing of the cognitive elements of global coherence was not meant to be exhaustive, neither is this list meant to be exhaustive. Rather, it is offered in an attempt to draw appropriate attention to largely implicit elements of a text which traditionally have been overlooked or pointedly excluded. We might recall that Halliday and Hasan seem to give equal status to both register and cohesion, the latter being the focus of their study. Indeed, according to Halliday and Hasan, "texture" (global coherence) is achieved through the mutually complementary relationship of "register" and "cohesion" (23). As noted above, the concept of warrants and all it entails may be regarded as the implicit and necessary part of a writer's register.

Halliday and Hasan define register as "the set of meanings, the configuration of semantic patterns, that are typically drawn upon under the specified conditions, along with the words and structures that are used in the realization of the meanings" (23). Halliday and Hasan thus 
acknowledge the essential nature of extra-textual elements in order for a text to evince global coherence, but they limit their work to the surface language of a text, deliberately and explicitly excluding register, and thus warrants, from their study of cohesion in English. Gutwinski goes even further with regard to extra-textual elements of global cohesion. As noted in chapter two (p. 47), he believes coherence to be unanalyzable in the linguistic sense because it deals with phenomena which "cannot be treated on a single level of analysis and some which are not open to linguistic analysis at all" (26). Such a position, which allows only for empirical data, bespeaks of the epistemological framework Naturwissenschaften, and is an exclusionary one which does not begin to address the complex and multi-layered elements which function to cohere an essay or composition.

The following list, then, is an attempt to account for at least some of the major elements of global coherence in the contextually salient perspective; these elements, though implicit, are nonetheless essential. Indeed, they may be the most pervasive and powerful of all the elements of global coherence, for they deal not only with epistemological frameworks, but also with one's values and belief systems. 
Examples of Epistemological Frames

Geisteswissenschaften: the inclusive frame which utilizes both intangible and tangible data

Naturwissenschaften: the exclusive frame which utilizes only tangible data

Examples of Central Metaphors

Cosmos: the metaphor which emphasizes the harmony, order, and balance exhibited in the universe

Growth: the metaphor which views the good in terms such as expansion or increasing consumption

Jungle: the metaphor which views life as the survival of the fittest

Chance: the metaphor which emphasizes the randomness and unpredictability of life

Fate: the metaphor which views life's events as foreordained

Journey: the metaphor which likens life to a trip having a definite beginning, interim passage(s), and destination

The Establishment: the metaphor which acknowledges a controling status quo

Money: the metaphor that life has a cash nexus and everything is viewed in relation to this nexus

Machine: the metaphor that life is mechanistic, and accordingly is analyzable and predictable

Stage: the metaphor that life is drama and requires various roles to be played

Examples of Sociological Models

dramaturgical

labelling

phenomenological

ethnomethodological 
Examples of Enabling Features Which Effect Warrants lexicon

grammatical structure

arrangement

thesis placement

prevalence of particular central cognitive processes rhetorical pattern of sentences

tone

\section{An Explicit-Implicit Continuum}

our treatment of the linguistic perspective of global coherence resulted in the continuum below:

$<------E X P L I C I T-----------------------I M P L I C I T----->$

repetition

anaphora

cataphora

ellipsis

ellipsis

It was noted that because of the mandatory explicitness of the linguistic elements of global coherence, all four categories--repetition, anaphora, cataphora, and ellipsis-are located at the explicit end of the continuum, but because ellipsis has an implicit component, it is also located at the implicit end of the continuum. 
It was also noted that unlike the linguistic elements of global coherence, which always have a mandatory, explicit component manifested in the text through and by language expressly for co-referential purposes, the cognitive elements of global coherence are often manifested in a liminal manner and serve as a threshold at which the explicit-implicit distinction blurs. Consequently, the explicit-implicit continuum with elements from both the linguistic and cognitive continuums approximated the following:

$<-----E X P L I C I T$ limen IMPLICIT

given/new relationship Gestalt

repetition

anaphora central

cataphora cognitive processes

ellipsis

ellipsis

The central cognitive processes were located at the limen position of the continuum because of the variable nature of their overt markers; at times, their overt markers are necessary, but often they are optional, depending on the rhetorical situation. Now, it is necessary to locate the elements of the contextually salient perspective of global coherence on the explicit-implicit continuum. 
The overwhelming use of language is not empirical reference, i.e., reference exclusively to the empirical here-and-now; rather, most language use is modal reference, i.e., reference to all situations and circumstances not in the empirical here-and-now. Just as the referents of this modal use of language are not located in the here-and-now, the contextually salient elements of global coherence are not located within the text. Accordingly, one can posit an explicit-implicit continuum as follows:

$\begin{array}{ll}\text { given/new relationship } & \text { Gestalt } \\ & \text { epistemological frames } \\ \text { central metaphors } \\ \text { sociological models } \\ \text { warrants }\end{array}$

central cognitive processes

repetition anaphora cataphora ellipsis ellipsis

This schema is far from complete, but it offers a set of elements from three different perspectives that may serve as a manageable framework within which one can better analyze and teach global coherence. The schema suggests a complex and multi-layered continuum of elements which function to globally cohere an essay or composition. While 
this continuum reflects an explicit-implicit dynamic, it does not represent a configuration which integrates the three global perspectives and their respective elements. In the next, and concluding, chapter of this study, such a configuration is offered, as well as implications for teaching student writers to produce globally coherent compositions. 
Works Cited

bear. The American Heritage Dictionary of the English Language. Boston: Houghton Mifflin, 1978 .

Brown, Richard. A Poetics for Sociology: Towards a Logic of Discovery for the Human Sciences. Boston: Cambridge $U$ P, 1979 .

Corbett, Edward. Classical Rhetoric for the Modern student. New York: Oxford U P, 1971.

Corder, Jim, and John Ruszkiewicz. Handbook of Current English. Glenview IL: Scott, Foresman, 1985.

Dilthey, wilhelm. Essay of Philosophy. Trans. Stephen Emery \& William Emery. NY: AMS Press, 1985.

---. Introduction to the Human Sciences. Ed. \& Trans. Ramon Betanzos. Detroit: Wayne state U P, 1988.

Fodor, Jerry. The Modularity of Mind. Cambridge MA: MIT P, 1983.

Glass, Arnold, Keith Holyoak, and John Santa. Cognition. Reading MA: Addison-Wesley, 1979.

Gutwinski, waldemar. Cohesion in Literary Texts. The Hague: Mouton, 1976.

Hairston, Maxine, and John Ruszkiewicz. The Scott, Foresman Handbook for Writers. New York: HarperCollins, 1991.

Halliday, M. A. K., and R. Hasan. Cohesion in English. London: Longman, 1976.

Hirsch, E. D., Jr. "Objective Interpretation." Critical Theory Since Plato. Ed. Hazard Adams. San Diego CA: HBJ, 1971. 1176-94.

Hodges, John, and Mary Whitten. Harbrace College Handbook. New York: HBJ, 1977.

Holy Bible. Ed. C. I. Scofield. New York: oxford U P, 1967 .

Jones, Roger. Physics as Metaphor. New York: Meridian, 1982 . 
Kaplan, Robert. "Cultural Thought Patterns in Inter-Cultural Education." Readings on English as a Second Language. Ed. Kenneth Croft. Cambridge MA: winthrop, 1980. 399-418.

Knoblauch, C. H., and Lil Brannon. Rhetorical Traditions and the Teaching of Writing. Upper Montclair NJ: Boynton/Cook, 1984.

Lakoff, George. "A Figure of Thought." Metaphor and Symbolic Activity 3 (1985-86): 215-25.

Lakoff, George, and Mark Johnson. Metaphors We Live BY. Chicago: U Chigago P, 1980.

McCrimmon, James. Writing with a Purpose. Boston: Houghton Miffiin, 1974 .

metaphor. The American Heritage Dictionary of the English Language. Boston: Houghton Mifflin, 1978 .

Perelman, C., and L. Olbrechts-Tyteca. The New Rhetoric. Trans. John Wilkinson and Purcell Weaver. Notre Dame IN: U Notre Dame P, 1971.

Richards, I. A. The Philosophy of Rhetoric. New York: Oxford U P, 1936 .

st. Clair, Robert N. "Language and the social Construction of Reality." Language Science 4 (1982): 211-36.

---. Social Metaphor: Essays in Structural Epistemology. Forthcoming.

Stewart, Donald. The Versatile Writer. Lexington: D. C. Heath, 1986.

Toulmin, Stephen. The Uses of Argument. Cambridge ENG: Cambridge U P, 1958 .

Waldron, T. Language and Mind. London: Routledge \& Kegan Paul, 1985. 


\section{CHAPTER V}

\section{SYZYGY}

This study in global coherence for the teacher of composition began with the following two passages from classical rhetoric's on the Sublime. Longinus wrote ". . we see skill in invention, and due order and arrangement of matter, emerging as the hard-won result not of one thing nor of two, but of the whole texture of the composition" (43). He continued:

Now, there inhere in all things by nature certain constituents which are part and parcel of their substance. It must needs be, therefore, that we shall find one source of the sublime in the systematic selection of the most important elements, and the power of forming, by their mutual combination, what may be called one body. (69)

I have sought to identify these "most important elements" so that teachers of composition, and particularly their students, will have a better idea of what a coherent essay or composition entails. Perhaps more importantly, teachers and students in composition classes may also have a better idea of why a particular paper fails to cohere and what might be done to remedy the lack of coherence.

Toward this end, three lines of inquiry were followed: a linguistic perspective, a cognitive perspective, and a contextually salient perspective. The linguistic perspective was investigated first, for, as a review of 
college handbooks revealed, what attention had been given the notion of coherence was given principally at the sentence level and restricted to the surface language of the sentence.

Three major works dealing with coherence from a linguistic perspective were analyzed: Halliday and Hasan's Cohesion in English, Gutwinski's Cohesion in Literary Texts, and Markels' A New Perspective in Cohesion in Expository Paragraphs. Excepting a portion of Markels' work, the analysis revealed a tendency to exclude extra-textual aspects of discourse.

The analysis of these works also resulted in the identification of linguistic elements of global coherence and their location along an explicit-implicit continuum. These linguistic elements serve a co-reference function, constitute sets with a relatively small number of words in a given text, occur frequently, and have a mandatory explicitness so that they can enable logical identity and consistency of reference. These elements are shown on the explicit-implicit continuum below.

$<------E X P L I C I T$ IMPLICIT

repetition

anaphora

cataphora

ellipsis

ellipsis 
The second line of inquiry, that of the cognitive perspective, investigated the roles of the umbrella concepts of the given/new relationship, Gestalt, and central cognitive processes. The central cognitive processes were seen as serving a vital and dual role in effecting global coherence, for they serve not only as "pathways" along which humans experience outer and inner reality, but also as the "nuts and bolts" of thought. They thus function to generate thoughts as well as to organize them. These central cognitive processes were demonstrated to be optional in many instances, and thus they are located at the limen along the explicit-implicit continuum, as shown below. $<-$ EXPLICIT limen IMPLICIT------>

given/new relationship Gestalt

repetition

anaphora central cognitive processes

cataphora

ellipsis

ellipsis

The third line of inquiry, that of contextual salience, explored the roles of epistemological frames, central metaphors, sociological models, and warrants as they serve to effect the global coherence of an essay or composition. It was found that much of the function of these elements is extra-textual and implicit, and that much of the language 
used to signify them is used at the interpretive level. These elements are pervasive and ubiquitous. Below, the contextually salient elements are located along the explicit-implicit continuum in relation to the elements of the linguistic and cognitive perspectives.

$\begin{array}{ll}\text { given/new relationship } & \text { Gestalt } \\ & \text { epistemological frames } \\ \text { central metaphors } \\ \text { sociological models } \\ \text { warrants }\end{array}$

central cognitive processes

repetition

anaphora cataphora

ellipsis

ellipsis

The elements listed above are not intended to be inclusive; rather, they are meant to break new ground in the study of coherence and to redistribute the burden of coherence from the sentence level and from the surface language of the text to a more inclusive and realistic tri-partite focus. In this sense, then, they may be thought of as the "certain constituents" to which Longinus was referring when he wrote ". . . there inhere in all things by nature certain constituents which are part and parcel of their substance" (69). 
All three sets of global elements--linguistic, cognitive, and contextually salient--interrelate in distinctive ways to achieve textual coherence. The linguistic elements create an explicit and consistent thread of co-reference, thus ensuring "the most fundamental principle of language: the normative principle of logical identity" (Waldron 197). This set of cohering elements performs the crucial role of maintaining the integrity of the nucleus of natural language logic, a nucleus which consists of logical identity and co-reference.

The cognitive elements encompass this nucleus of logical identity and co-reference and enable the generation and organization of content around and about it. These elements cross all registers and semantic domains and are universal for all humans. Significantly, central cognitive processes are located at the limen of explicitnessimplicitness, and their life on the boundary allows them to shift from the explicit to the implicit as linguistic convention or concerns of salience dictate.

The contextually salient elements encompass the cognitive elements as well as the linguistic elements and establish the expectations and constraints of the rhetorical situation. These elements are not only the most implicit, but also the most pervasive, the most ubiquitous, and the most circumscribing. 


\section{A Visual Metaphor of Global Coherence}

The visual metaphor below offers another way of viewing the elements of global coherence and their interrelationships.

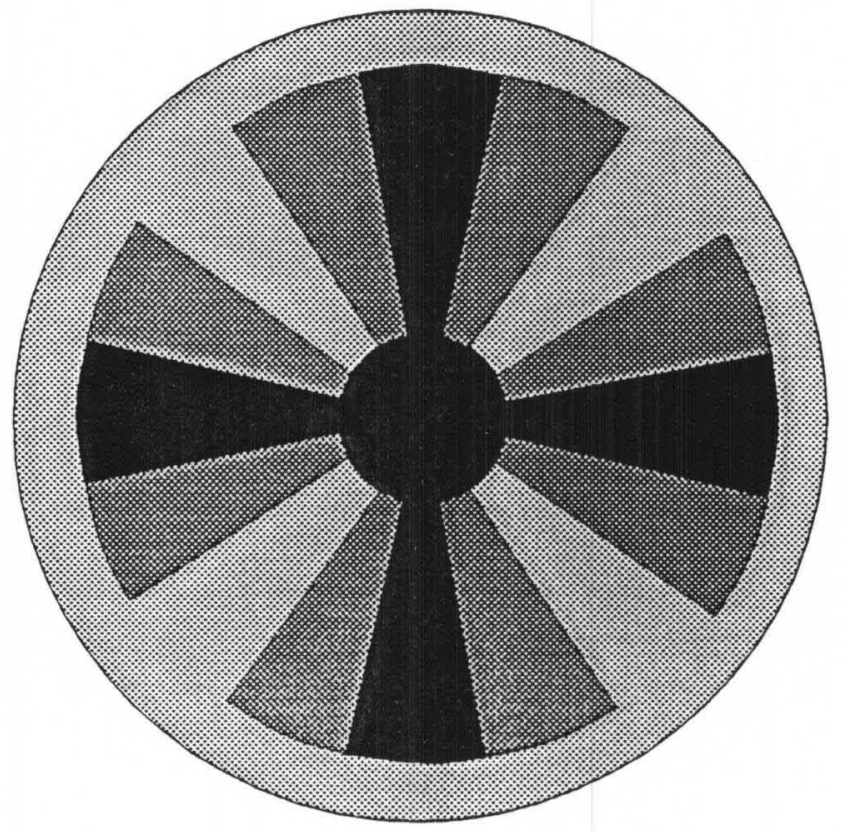

Contextually Salient Perspective epistemological frames central metaphors sociological models warrants ellipsis

most implicit most circumscribing most pervasive establish expectations and constraints of the rhetorical situation

Cognitive Perspective given/new relationship

Gestalt central cognitive processes

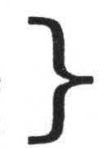

located at the explicit-implicit limen cross all domains and registers universal for all humans effect both invention and arrangement

Linguistic Perspective

repetition anaphora cataphora ellipsis most explicit

effect reference, co-reference, and

logical identity, thus comprising the nucleus of natural language logic 
No metaphor is completely descriptive. The metaphor offered above, adapted from Niels Bohr's model of the atom, does not capture the pervasiveness of contextual salience. In order for it to do so, the model would have to be three dimensional with fibers or force fields of a constraining nature extending from it and throughout the three "levels." Nonetheless, this metaphor captures several vital aspects of the global perspectives.

For instance, the overarching nature of contextual salience is accurately represented, as is the nucleus of natural language logic, the integrity of which is maintained by the linguistic level. Too, the visual metaphor aptly places the cognitive level, which is liminal regarding explicit and implicit properties, between the most explicit level, the linguistic level, and the most implicit level, the contextual salience level.

Significantly, the three "concentric" levels of the visual metaphor comprise a continuum of more-or-less discrete force fields potentially in contact with any other force field on any level, thus simulating the property of parallel distributed processing.

Finally, instead of confining the focus of coherence to the surface of a text at sentence level, this visual metaphor enables one to comprehend better the multi-layered complexity inherent in a globally coherent essay or composition. 


\section{Pedagogical Implications}

This approach to global coherence offers the teacher of composition distinct advantages over the conventional accounts grounded principally in linguistic description of the surface language of a text at the sentence level. Seven major advantages of this approach are that it

- allows for a full recognition of the parts-to-whole and whole-to-parts relationship

- relates the parts-to-whole and whole-to-parts aspects to bottom up and top down processing

- emphasizes the connections among rhetoric, the "real world," and the elements of global coherence

- addresses both the linear and non-linear aspects of global coherence and text production

- demonstrates that the abbreviation "coh" is insufficient to indicate problems in coherence

- shows how central cognitive processes effect both invention and arrangement

- provides the basis for determining the order in which the global perspectives may be taught.

The first advantage of this approach is it allows for a full recognition of the parts-to-whole and whole-to-parts relationship. Global coherence was defined as the comprehensive, systematic connection of constitutive elements of a text of logical discourse, with a consistent emphasis on the totality of the text and on the interrelatedness of its constituents (chapter I, p. 2). Two significant notions are couched in this definition: the 
notion of parts, i. e., the "constituents," and the notion of whole, i.e., the "totality of the text." The parts-to-whole and whole-to-parts relationships are depicted in both the explicit-implicit continuum and the visual metaphor. The former offers constitutive elements along an explicit-implicit continuum; these constitutive elements comprise a totality resulting in the global coherence of an essay or composition. Similarly, the visual metaphor offers a totality of constitutive elements in the form of the global perspectives--the linguistic, cognitive, and contextually salient perspectives. In both the explicitimplicit continuum and the visual metaphor, as well as in the definition of global coherence, the parts-to-whole and whole-to-parts relationships evince themselves as integral to an understanding of global coherence. It follows, then, that an acute awareness of this relationship ought to be central to one's pedagogy in the composition class. The second advantage of this approach is it relates the parts-to-whole and whole-to-parts aspects of global coherence to bottom up and top down processing. Any approach toward coherence that focuses on one particular language level, as in the Harbrace college Handbook with its focus on the sentence level, or on one discourse level, as in Mccrimmon's Writing with a Purpose with its focus on the paragraph, does not go far enough. Instead, one needs an 
approach which emphasizes the parts-to-whole and the whole-to-parts relationships.

If the composition teacher facilitates bottom up processing of global elements in conjunction with top down processing, i.e., if the student writer is encouraged to see "the big picture" of the composition assignment, of what sort of composition or essay might result, while also being encouraged to see how the global elements may combine to cohere a text, then that student's prospects for a successful paper are enhanced. Hence, the student writer would be actively engaged in dual tasks. An approach incorporating the parts-to-whole/whole-to-parts dynamic also meshes with recent studies in learning theory which suggest that humans as individuals have different cognitive styles. Some writers tend to begin a composition with "the big picture" and then "flesh it out," while others begin with several small observations and details and then build upon them until a coherent composition emerges.

The third advantage of this approach is its emphasis on the connections among rhetoric, the "real world," and the elements of global coherence. This emphasis stems from the tri-partite nature of the approach, and that a significant portion of the elements effecting global coherence are extra-textual or implied. Thus, it is incumbent upon the composition teacher to ensure that student writers understand the significance, both rhetorical and "real 
world," of global elements such as warrants, central metaphors, sociological models, and perhaps even epistemological frames. This does not mean, of course, that a composition course be turned into miniature psycho- and sociolinguistic courses, but this does mean that these global elements need to be expressed in language appropriate to the course level, for often they are crucial to top-down or whole-to-parts processing. And of course, these elements are part-and-parcel to a cogent understanding of the rhetorical situation.

The fourth advantage of this approach is it addresses both the linear and non-linear aspects of global coherence and text production. If the cognitive perspective, and particularly if the contextually salient perspective, is accepted, then a pedagogical implication concerning linearity emerges: many of the cohering elements of successful composing are not linear. Composition teachers must address this circumstance. Compositionalists must engage student writers in non-linear thought, must stimulate non-linear thought, and then face the larger challenge of coaching and coaxing student writers into articulating their non-linear thought into linear Edited American English. Here a question about the traditional college essay arises, however. Will the future college essay be solely one of linear Edited American English, or will it take the form of a multi-media presentation saved on a computer disk? 
Perhaps traditionalists need not be too alarmed, though, for even if the future holds such a college essay, they can rest fairly secure that the multi-media essay will require an ample amount of linear articulation.

The fifth advantage of this approach is it demonstrates that the abbreviation "coh" is insufficient to indicate problems in coherence. If one agrees that many elements, such as those from the linguistic, cognitive, and contextually salient perspectives, combine to cohere an essay or composition, one might also raise the following question: before a composition teacher responds to a problem of coherence in a student paper by writing "coh" on the paper, ought not that composition teacher first discern the nature of the incoherence and be prepared to offer a corrective tactic or strategy to the student writer apropos the error? A related question is, if the linguistic elements of global coherence deal mostly with the maintenance of identity, if central cognitive processes deal mostly with the generation and organization of content, and if contextually salient elements deal mostly with expectations and constraints regarding lexicon, arrangement, tone, and so forth, then will a simple "coh" suffice if a student writer has a problem in any one of these kinds of cohering elements? Put another way, should a composition teacher be more specific with regard to symbols used to mark problems in coherence? 
The sixth advantage of this study is it shows how central cognitive processes effect both invention and arrangement. Traditionally, words such as however, although, and therefore have been viewed as conjunctive adverbs or subordinate conjunctions, depending on whether they relate main clauses or subordinate clauses. From a purely grammatical or surface language view, this may be acceptable, but this position overlooks the shared nature of all such transition words. Such words not only bridge, but actually are channels or kinds of thought as the section on central cognitive processes indicates (chapter III, pp. 87102). Central cognitive processes not only enable one to generate thoughts, but also to organize them. Because of this double articulation, they are arguably the best examples illustrating the fluid relationship between invention and arrangement. Ought they not, then, receive special emphasis in the teaching of both invention and arrangement of a composition?

The seventh advantage of this approach is it provides the basis for determining the order in which the global perspectives may be taught. Should the linguistic, cognitive, and contextually salient perspectives be taught collectively? Or, perhaps, should only the cognitive and contextually salient perspectives be taught, and student writers having serious problems with the elements of the linguistic perspective be sent to remediation? With the 
latter view, would it be good to teach the contextually salient view first by introducing its elements and the expectations and constraints they signify? As noted earlier, these could be taught through the rhetorical situation, through warrants, and through an introduction to the levels of language use. Then, central cognitive processes could be taught along with their dual role of generating and organizing content vis-a-vis the constraints and expectations of the contextually salient elements. The composition teacher could then monitor for problems with the linguistic elements.

\section{Sygyzy}

As far as is known, no other beings in the cosmos have been accorded the scope and degree of spoken ability that humans have, yet as wonderful as speech is, it alone would not have taken humans very far from the cave. Written language, however, with its ability to hypostasize thought, thus enabling permanent records, reflection, and extended discourse capable of revision, has exposed humans to seemingly infinite frontiers within the human psyche, and outside it, to the far, unfathomable reaches of space. Surely, then, to fashion coherent, extended, written discourse for a specific purpose to a specific audience regarding a specific occasion--that is, to fashion a 
successful essay or composition--is to participate in a uniquely human endeavor.

In the discipline of astronomy, one learns of a phenomenon called syzygy. Syzygy is a natural alignment of elements--three celestial bodies--but it is not a continuous alignment, and it occurs only when certain conditions and perspectives coalesce; similarly, one may envision a kind of syzygy in the coalescing of conditions and perspectives when the writer successfully aligns the "certain constituents" of the three global perspectives which are "part and parcel" of a globally coherent essay or composition. These constituents are myriad, intricate, and amazingly interwoven, yet if the student writer can learn how to align the perspectives and coalesce their elements into a successful essay or composition, then he or she may well experience a sense of the sublime which Longinus extolls. It is my hope that this study will in some way help the teacher of composition guide his or her students in the uniquely human endeavor of generating successful essays. 


\section{Works Cited}

Gutwinski, Waldemar. Cohesion in Literary Texts: A study of Some Grammatical and Lexical Features of English Discourse. The Hague: Mouton, 1976.

Halliday, M. A. K., and R. Hasan. Cohesion in English. London: Longman, 1976.

Harbrace College Handbook. John C. Hodges and Mary E. Whitten. New York: HBJ, 1977.

Longinus. Longinus on the Sublime. Trans. W. R. Roberts. Cambridge ENG: Cambridge U P, 1935.

Markels, Robin B. "Cohesion Paradigms in Paragraphs." College English 45 (1983): 450-64.

---. A New Perspective on Cohesion in Expository Paragraphs. Carbondale: Southern Illinois U P, 1984.

McCrimmon, James. Writing with a Purpose. Boston: Houghton Mifflin, 1974 .

Waldron, T. P. Principles of Language and Mind. London: Routledge \& Kegan Paul, 1985. 


\section{APPENDIX I}

Halliday and Hasan argue in Cohesion in English that the cohering operations of co-reference, substitution, ellipsis, conjunction, and lexical cohesion are non-structural. This study in global coherence, however, argues that co-reference and ellipsis are forms of substitution and that substitution is structural in nature. Details of this argument follow: fundamental to Halliday and Hasan's approach to textual analysis is the notion of the tie, which they define as "a single instance of cohesion, a term for one occurrence of a pair of cohesively related items" (5). An example is "the relation between them and six cooking apples" in the following:

[2:1] Wash and core six cooking apples. Put them into a fireproof dish.

A tie, then, is "best interpreted as a RELATION between

- . two elements," one of which presupposes the other; a tie is "also DIRECTIONAL," in that it is anaphoric "presupposed element preceding") or cataphoric ("presupposed element following") (329). Ties may be "IMMEDIATE," "MEDIATED," or "REMOTE" as the following passage illustrates:

[2:2] The last word ended in a long bleat, so like a sheep that Alice quite started (1). She looked at the Queen, who seemed to have suddenly wrapped herself up in wool (2). Alice rubbed her eyes, and looked again (3). She couldn't make 
out what had happened at all (4). Was she in a shop (5)? And was that really--was it really a sheep that was sitting on the other side of the counter (6)? Rub as she would, she could make nothing more of it (7). (qtd. in Halliday \& Hasan 330)

Because the she in sentence (2) refers to Alice in sentence (1), and the two sentences are contiguous, the tie is immediate. If the ties occur in three or more contiguous sentences, then the ties are "MEDIATED," as for the she in (5) and Alice in (3); the she in (4) mediates because it, too, like the she in (5), presupposes Alice in (3). If a tie exists across a number of sentences with no mediated tiesin the intervening sentences, then the tie is "REMOTE," as for Rub as she would in (7) and Alice rubbed her eyes in (3).

In order for one to make sense of Rub as she would, one has to refer back across intervening, non-mediating sentences to Alice rubbed her eyes in (3) (Halliday \& Hasan $330-31)$

Cohesive ties are of five types, reflecting the five sub-categories of cohesion: co-reference, substitution, ellipsis, conjunction, and lexical cohesion (4).

Halliday and Hasan treat the cohesive tie of co-reference as a "semantic," not a "grammatical," relation and view it as prior to the other types of cohesive ties (most probably because they consider it a non-structural 
form of cohesion). Co-reference is viewed directionally and semantically.

Co-reference viewed directionally is of two broad categories: exophoric and endophoric.

Exophoric co-reference deals with co-reference outside the text, i.e., to elements of the register, and thus is considered "situational" co-reference. Halliday and Hasan, drawing from Bernstein, illustrate exophoric co-reference with the following example:

[2:3] They're playing football and he kicks it and it goes through there it breaks the window and they're looking at it and he comes out and shouts at them because they've broken it so they run away and then she looks out and she tells them off. (qtd. in Halliday \& Hasan 35)

In order for this passage to "make sense," one must have information concerning the referents of the pronouns, i.e., who they are, and perhaps what their roles are in the context of the passage (35). Significantly for rhetoricians, Halliday and Hasan exclude exophoric reference from their study of cohesion in English.

Endophoric co-reference deals with co-reference between items in a text and is considered "textual" co-reference. Endophoric co-reference is the co-reference of primary concern for Halliday and Hasan. Endophoric co-reference subdivides into anaphoric and cataphoric co-reference, with anaphoric referring back to an element located earlier in 
the text and cataphoric referring forward to an element in the text, as the following examples indicate:

[2:4] anaphoric co-reference

Jon swims very well; he swam the English Channel.

[2:5] cataphoric co-reference

What I am going to say will interest you immensely.

Susan has decided to study medicine in Tibet. Co-reference viewed semantically is of three types:

personal, demonstrative, and comparative. Personal

co-reference is "by means of function in the speech

situation" (37) and is exemplified in the following

sentences :

[2:6] I bought a new car yesterday. (pronoun)

(One can also argue that $I$ is substituting for a proper noun which lies outside the text, is therefore exophoric (cf. [2:3], not endophoric, and if one were to follow Halliday and Hasan's logic, the use of I would then not be textual. However, the definition of global coherence encompasses exophoric co-reference. Regardless of the directionality, it is argued here that the use of I in this sentence is an example of substitution.)

[2:7] The salesman gave me a good deal. (pronoun)

(Again, the pronoun me substitutes for a proper noun.)

[2:8] Now the car is mine. (determiner)

(Here, mine substitutes for the noun phrase my car.)

[2:9] Now my bank account is nearly empty. (determiner)

(For this last sentence, one can argue that my functions as a modifier in a noun 
phrase, not as a co-referent. Thus far, the uses of Halliday and Hasan's semantic co-reference are primarily that of substitution.)

Halliday and Hasan's second type of co-reference, demonstrative co-reference, is "essentially a form of verbal pointing" (deixis) according to proximity (57), and is realized in words such as this/these, here (near), that/those, there, then (far), and the definite article the. (Halliday and Hasan argue that the should be included with the deictic words because the is a reduced form of that, and the, while making its referent definite, may refer to something in the register--exophorically--and thus qualifies as cohesive. It should be noted, however, that the focus of Halliday and Hasan throughout their book is on endophoric co-reference; thus, inclusion of the at the same status as the other deictic words because of an exophoric property is debatable.)

Examples of demonstrative co-reference are the following:

[2:10] I like the lions, and I like the polar bears. These are my favorites (60).

[2:11] We're going to the opera tonight. This'll be our first outing for months $(60)$.

(One can argue that in [2:10], These is either a truncated or elliptical construction substituting for the noun phrase these animals, and that in [2:11], This substitutes for the noun phrase our going.) 
Halliday and Hasan state that what "probably accounts for the majority of all instances" of demonstrative co-reference is extended co-reference, in which the demonstrative refers to a process or situation:

[2:12] They broke a chinese vase.

That was very careless. (66)

That refers to the process involved which resulted in the breaking of the vases. (One can argue that That is actually another example of substitution: That $=$ the breaking of the vase.)

Halliday and Hasan's third type of co-reference, comparative co-reference, is of two kinds, general and particular. General comparative co-reference is based on the notions that "likeness is a referential property," and a "thing cannot just be 'like'; it must be 'like something'" (18). The comparison "may be in the situation or in the text," it may be anaphoric and cataphoric, and it may be structural or non-structural, and if it is non-structural and in the text, then it is cohesive (78). (I argue in chapter three that the latitude of situations and conditions under which comparison operates, along with other reasons, makes it a central cognitive process and is not a form of co-reference.)

Examples of anaphoric and cataphoric general comparative co-reference are, respectively, the following: [2:13] Sam is at the door; I was expecting someone different. 
(One can argue that different is a truncated or elliptical form of the phrase different than sam, and, in turn, that this phrase is a truncated form of the underlying clause a person who differs from sam, which modifies someone. Thus, different is not used as co-reference, but is used to indicate comparison, which is treated in the cognitive perspective of global coherence.)

[2:14] She's a different breed than the one we had before.

(Here, one can again argue that different than is not used as co-reference, but is used to indicate comparison, which is treated as a central cognitive process in the cognitive perspective in chapter three of this study.)

Additionally, Halliday and Hasan tell us, "the comparison may be internal--the likeness expressed as mutual likeness without a referent appearing as a distinct entity" (78), as the following illustrates:

[2:15] Most people have the same breakfast every day. (meaning 'the same as every other day') (80)

[2:16] The candidates gave three similar answers. (meaning 'similar to each other') (80)

[2:17] All parties showed an identical reaction to the news. (meaning 'reacted in the same way as each other') (80)

(In each of these cases, one can argue that the words the same as, similar, and identical principally indicate comparison, a central cognitive process, and not co-reference, i.e., none of the expressions share referents, but they indicate referents which share commonalities.)

Particular comparative co-reference "expresses comparability between things in respect of a particular property 
[2:18] We don't need any more mistakes.

[2:19] The hare ran faster.

[2:20] The sun shines brighter.

(One can make two additional arguments here: 1) each of these examples have elliptical constructions, e.g., [2:18] "We don't need any more mistakes (than we already have)" or [2:19] "The hare ran faster (than the tortoise) ";

2) comparison, not co-reference, is indicated by comparative forms more and -er.)

Curiously, Halliday and Hasan end their discussion of co-reference with the statement that "the different forms of cohesion are nowhere sharply set apart one from another" $(87)$.

In sum, from the examples above, one can make two observations. First, much of co-reference can be seen as a form of substitution. Second, those examples of co-reference which are not substitution can be seen as forms of comparison, a central cognitive process. Such recategorization simplifies the linguistic perspective of global coherence.

Halliday and Hasan's second sub-category of cohesion is substitution. Halliday and Hasan argue that substitution is a relation between linguistic items, such as words or phrases; whereas co-reference is a relation between meanings. . . . co-reference is a relation on the semantic level, whereas substitution is a relation on the . . level of grammar and vocabulary. (89)

(They add that ellipsis "can be defined as substitution by zero. . . but the mechanisms involved in the two [substitution and ellipsis] 
are rather different, . . and in the case of ellipsis, fairly complex" [88-89].)

Examples of co-reference are the following:

[2:21] John has moved to a new house.

He had it built last year. (54)

[2:22] Who are those colourful characters?

Those must be the presidential guards.

[2:23] The little dog barked as noisily as the big one. (82)

Examples of substitution are the following:

[2:24] My axe is too blunt. I must get a sharper one. (89)

[2:25] What kind of engines do you want?

ones with whistles, or ones without? (92)

[2:26] These grapefruit smell more bitter than the last ones we had. (109)

(Halliday and Hasan argue that ones is an example of substitution if the grapefruit also taste more bitter, but if they taste the same, then ones is an example of co-reference, not substitution.)

Although Halliday and Hasan argue co-reference occurs at the "semantic level," and that substitution occurs at the level of "grammar" and "vocabulary," when one examines their examples, one finds the distinction to be nebulous, for each of their co-reference examples, [2:21] and [2:22], and their substitution example, [2:25], indicate the same referent; and their co-reference example, [2:23], and each of their substitution examples, [2:24] and [2:26], indicate different referents. What one does find in common for all examples is that substitution of a pro-form occurs. Thus, if one omits the co-reference/ substitution distinction (or the 
semantic/grammatical distinction), one can avoid altogether the sort of puzzling, "smell" vs. "taste" contretemps presented by the grapefruit example $[2: 25]$.

Substitution is of three types: nominal, verbal, and clausal. Nominal substitution uses the words one, ones, or same; verbal substitution uses the word do; and clausal substitution uses the words so or not. These word lists are virtually inclusive, with only a few exceptions: the expressions do so, and do the same, about which there is some "indeterminacy," and general words such as thing, "where substitution shades into lexical cohesion" (91). Examples of nominal substitution are found in $[2: 24]$, $[2: 25]$, and [2:26] above.

Examples of verbal substitution are in the following sentences: - . the words did not come the same as they used to do. (substitution for come) (112)

I don't know the meaning of half those long words, and, what's more, I don't believe you do either!

\section{(substitution for know the meaning of half those long words) (112)}

Halliday and Hasan note that for do substitution, "the contrastive element which provides the context for the substitution is located within the same clause," as in [2:27] and [2:28] above, unlike in clausal substitution (below), in which "the clause is presupposed, and the contrasting element is outside the clause" (130). 
Clausal substitution occurs in the environment of hypotaxis, i.e., one clause depends on another semantically, but not through structural embedding (136). Examples of clausal substitution are in the following sentences:

[2:29] Is there going to be an earthquake?

It says so. (so substitutes for the entire clause there is going to be an earthquake, with says serving as the contrastive environment) (130)

[2:30] (reported clause)

'. . if you've seen them so often, of course you know what they're like.'

'I believe so,' Alice replied thoughtfully.

[2:31] (conditional clause)

Everyone seems to think he's guilty. If so, no doubt he'll offer to resign. (134)

[2:32] (modalized clause)

'Oh, I beg your pardon!' cried Alice hastily, afraid that she had hurt the poor animal's feelings. 'I quite forgot you didn't like cats.'

'Not like cats!' cried the Mouse, in a shrill, passionate voice. 'Would you like cats if you were me?'

'Well, perhaps not,' said Alice in a soothing tone: . . (134)

Lastly, regarding the use of not, Halliday and Hasan relate that "the negative form of the clausal substitute is not" (133), as in the following example:

[2:33] Has everyone gone home? I hope not.

Halliday and Hasan's treatment of substitution not only offers numerous examples illustrating how it enables cohesive ties in texts, but it also delineates kinds of substitution--nominal, verbal, and clausal, and in their contrast of verbal and clausal substitution, they draw 
attention to the hypotactic environment, an environment which accounts for inter-clausal cohesive ties.

Ellipsis is the third major sub-category of cohesion in Halliday and Hasan's schema, and although they state that "ellipsis is simply 'substitution by zero," they argue that for their purposes, it is "more helpful to treat the two [substitution and ellipsis] separately" because "they are two different kinds of structural mechanism, and hence show rather different patterns" (142). (It is interesting to note what may be some inconsistency on Halliday and Hasan's part in their using a structural property, i.e., "kinds of structural mechanism," to justify their treatment of ellipsis, while they continue to categorize ellipsis as "non-structural.")

Halliday and Hasan seem a bit uncertain as to how to justify their assigning ellipsis unto its own category, for in one sentence they write "we can take as a general guide the notion that ellipsis occurs when something that is structurally necessary is left unsaid," and in the very next sentence they state "that the essential characteristic of ellipsis is that something which is present in the selection of underlying ('systemic') option is omitted in the structure--whether or not the resulting structure is in itself 'incomplete'" (144). Then, by way of summary, they state again that

The difference between substitution and ellipsis is that in the former a substitution counter occurs in the 
slot, and this must therefore be deleted if the presupposed item is replaced, whereas in the latter the slot is empty--there has been substitution by zero. (145)

Halliday and Hasan do not offer examples to illustrate this difference; however, one might assume that the following sentences illustrate how "substitution counter occurs in the slot," and how it "must therefore be deleted if the presupposed item is replaced" (145):

[2:34] original: John is building a house.

[2:35] substitution: He is building a house.

(He is the "substitution counter" and presupposes John.)

By replacing the presupposed item, John, with sue, one has [2:36] original: Sue is building a house. [2:37] substitution: She is building a house.

clearly, the substitution counter is not deleted, but merely replaced by another substitution counter. Consider an example with ellipsis, i.e., substitution by zero:

[2:38] original: One rabbit ran fast, and another rabbit ran slowly.

[2:39] substitution: One rabbit ran fast, and another (zero) ran slowly.

By replacing the presupposed item, rabbit, with dog, one has

[2:40] original: One dog ran fast, and another dog ran slowly.

[2:41] substitution: one dog ran fast, and another (zero) ran slowly. 
Hence, the structural mechanisms involved are not of "two different kinds" (142) unless one assumes the "substitution counters", i.e., the instantiated nominal, verbal, clause, or zero items, to differ in non-semantic ways; further, the very same structural mechanism occurs, viz., the structural operation of substitution of co-referential items. Moreover, the underlying semantic status, not surface representation, of the "presupposed item" and the "substitution counter" is the determining factor in this aspect of cohesion: their underlying semantic status must be that of co-reference, and it matters not whether the substitution counter is zero or an instantiated nominal, verbal, or clause. The structural operation which effects the substitution is identical, and co-reference of the presupposed item and the substitution item ensures comprehension.

Halliday and Hasan also argue that much of the distinction between substitution and ellipsis rests on the notions of single-element omission and branching clauses. Halliday and Hasan hold that single-element omission does not occur "WHERE THAT ELEMENT IS OTHERWISE OBLIGATORY" (205), as in the following examples:

[2:42] Has she taken her medicine?

[2:43] She has taken.

(in this unacceptable sentence, the single element, the complement, has been omitted) (202) 
However, one should consider an example of theirs before accepting their argument. In the following two sentences, the second sentence omits a single element, the complement, but according to Halliday and Hasan, this is not ellipsis because it is not "an instance of omission, and involves no presuppositions of any kind" (204), but rather an example of a systematic variant "in which nothing is omitted, any more than an expression of time or place can be said to be 'omitted' from a clause which does not contain one" (204). [2:44] Simon's playing.

[2:45] Let's not interrupt. (204)

First, it is arguable that something has been omitted on two counts. A sui species feature of English is its tendency toward the pattern subject-Verb-object (or Complement); English is commonly referred to as an svo language, and as such, native speakers of English usually deem a subject-Verb sentence incomplete if the verb is used in a transitive sense. For example, most native speakers of English find incomplete the following utterance if no object has been previously identified:

[2:46] Let's watch. (or Let's not watch.)

Likewise incomplete is,

[2:47] Let's interrupt. (or Let's not interrupt.) Native speakers would feel something had been omitted in [2:46] and in [2:47]. Likewise, if a native speaker is presented with the sentences 
[2:48] Simon's playing.

[2:49] Let's not interrupt.

and then is asked "Let's not interrupt 'what?'" he or she will normally answer "Simon" or "Simon's playing."

Thus, it seems that an omission has occurred in the sentence "Let's not interrupt." Halliday and Hasan do not explain the term "systematic variant," but whatever it is, one cannot deny the native speaker's intuition that an omission has occurred in "Let's not interrupt." Although the native speaker might not categorize it as such, it is an omission of a single element. Moreover, such an omission is not the same as the "omission" of "time" or "place" from a sentence, since virtually all utterances assume the metaphysical constants of time and place. Indeed, that is why they are "unmarked" in dialog, and why speakers signify a specific, non-metaphysical meaning of time and place by using definite, explicit "markers" such as the words here, now, there, and then whenever such reference is necessary for coherence.

Much of the rest of the argument that ellipsis is something more than zero substitution and hence merits its own category lies with ellipsis in question-and-answers such as the following:

[2:50] Is it Tuesday?

[2:51] I don't know. (212)

[2:52] Can you make it stand up? 
[2:53] If you keep still. (213)

[2:54] When did they cancel the booking?

[2:55] Did they? (213)

[2:56] John's coming to dinner.

[2:57] John? (215)

[2:58] John's coming to dinner.

[2:59] And Mary? (215)

In these cases, Halliday and Hasan do not contest the

omission as they do in sentences such as

[2:60] Simon's playing.

[2:61] Let's not interrupt. (204)

Finally, and perhaps most telling for the composition teacher who deals with problems in ellipsis resulting from tangled clauses in student writing, Halliday and Hasan argue that ellipsis does not occur in the following "branched" clauses:

[2:62] Either Peter will play his cello, or Sally her guitar. (203)

[2:63] The cat catches mice in the summer. -And the dog rabbits. (203)

[2:64] The cat won't catch mice in winter. -Nor the dog rabbits. (203)

[2:65] Sybil takes coffee very strong, but Joan very weak. (203)

Halliday and Hasan disqualify these sentences from exhibiting ellipsis on two grounds: 1) ellipsis for them involves "a form of pre-supposition between sentences," not within a sentence (203); and 2) the omission deals with the 
omission of "single elements of clause structure (as well as structures of any other rank)," i.e., with structure, and "we [Halliday and Hasan] are confining our definition of ELLIPSIS to its non-structural, cohesive sense" (203). Accordingly, Halliday and Hasan argue that [2:63] and [2:64] do not exhibit ellipsis because, in fact, they are actually one sentence.

[2:66] The cat catches mice in the summer. -And the dog rabbits. (203)

[2:67] The cat won't catch mice in winter. -Nor the dog rabbits. (203)

However, consider the following versions of Julius Caesar's famous triplet:

[2:68] I came to Gaul.

I saw Gaul.

I conquered Gaul.

[2:69] I came.

I saw.

I conquered.

[2:70] I came; I saw; I conquered.

[2:71] I came, I saw, I conquered.

Is [2:68] three sentences? Most composition teachers would probably respond yes. Does ellipsis occur in example [2:68]? Most composition teachers would probably respond no. Is [2:69] three sentences? Again, most composition teachers would respond yes. Does ellipsis occur in $[2: 69]$ ? Most composition teachers would probably respond yes. Is [2:70] three sentences? Here most composition teachers might hesitate. Is the semicolon a weak period, making 
[2:70] three sentences, or is the semicolon a strong comma, making [2:70] a single sentence? According to Halliday and Hasan, if one views $[2: 70]$ as three sentences, then ellipsis occurs, but if one views $[2: 70]$ as a single sentence, then ellipsis does not occur. Is [2:71] three sentences? Most composition teachers would respond no, that $[2: 71]$ is a single sentence.

Does ellipsis occur in $[2: 71]$ ? Most composition teachers would respond yes, ellipsis does occur. How can this be? Does ellipsis, a significant feature of cohesion, hinge on whether a string of clauses is separated by semi-colons, commas, or periods? surely not, for the semantic relationships are the same in each of the examples. Moreover, Halliday and Hasan argue that sentences like those below do not exhibit ellipsis because in each case the omission deals with the omission of "single elements of clause structure (as well as structures of any other rank)," and "we [Halliday and Hasan] are confining our definition of ELLIPSIS to its non-structural, cohesive sense" (203): [2:72] Either Peter will play his cello, or sally her guitar. (203)

[2:73] Sybil takes coffee very strong, but Joan very weak. (203)

However, the position regarding the omission of a single element can be countered with Halliday and Hasan's own example below in which a single element has been omitted. [2:44] Simon's playing. 
[2:45] Let's not interrupt. (204)

This argument, as stated earlier, is based on the svo (Complement) tendency in the English language. The native speaker intuits that something has been omitted in [2:45] and will easily supply a suitable element to "complete" the sentence. In addition, such an omission, contrary to Halliday and Hasan's position, is not the same as the "omission" of "time" or "place" from a sentence, but instead is an omission of a situation- specific element unique to that speech act.

In light of the above arguments, and in light of Halliday and Hasan's uncertainty over the status of ellipsis, I will, for the purposes of this study in global coherence, consider ellipsis a form of substitution, and one which is achieved through a structural operation involving the substitution of a zero item co-referential with the presupposed item. (For additional arguments supporting this position, one can refer to Dressler, Lakoff, Green, Dougherty, and Steinitz.) 


\section{APPENDIX II}

Jerry Fodor's functional taxonomy of cognition may be thought of as a cognitive flow among the following components: INPUT OF DATA $=>$ TRANSDUCER $=>$ INPUT SYSTEM (MODULE) => CENTRAL SYSTEM. These components are described in more detail below.

INPUT OF DATA consists of data input through any of the sensory channels, i.e., visual, auditory, tactile, olfactory, or taste. For example, input of data along the visual channel would trace the photons as they enter the visual channel and make their way through the channel to a transducer.

TRANSDUCERS put all input data into a particular format without any change in the content of the data. To quote Fodor: transducers "preserve the informational content of their inputs, altering only the format in which the information is displayed" (41).

INPUT SYSTEMS (MODULES) "mediate between transducer outputs and central cognitive mechanisms by encoding the mental representations which provide domains for the operations" of the CENTRAL COGNITIVE SYSTEMS (42); modules "pair transduced representations with formulas in the domains of central processes" (70) involving "mediated mappings from transducer outputs onto percepts--mappings that are effected via the computation of interlevels of 
representation of the impinging stimulus" (60). The following is a descriptive list of the more important characteristics of modules:

informationally encapsulated: there is limited, if any, access to information outside the module itself during input processing

domain specific: "the range of inputs for which [a module] computes analyses" is limited (103)

limited central access: only "the final consequences of input processing" are available to central systems (56)

hardwired/stable: "the grain of their physical architecture quite closely parallels the grain of their virtual architecture [sets of programming instructions]" (37)

computationally autonomous: all that is necessary for performance of the inference-like operations is contained in the module's neuro-anatomy

computationally local: stimulus driven; insensitive to an individual's belief system; a module may not access other modules during processing, but may access memory at or near completion of the process

shallow outputs: e.g., "the visual analysis system can report only upon the shapes and colors of things," not about photons (this demarcates perception and cognition: "all higher-level integrations," i.e., above shapes and colors of things, is post-perceptual)

not assembled: not constructed of simpler, more basic systems

mandatory: the individual has no choice in a module's operation

fast: much faster than the $250 \mathrm{milliseconds}$ required for shadowing (repeating what one is hearing) 
specific breakdown pattern: a pathology can cause a module to malfunction and evince behavior peculiar to the module, e.g, agnosia or aphasia

Modules, then, are "computationally elaborated" (83) and work from the sensory channels and language. Each module acts as a computational-confirmational mechanism "which projects and confirms a certain class of hypotheses on the basis of a certain body of data" (68).

An available hypothesis might be a word sequence that could be constructed from "entries in the subjects's mental lexicon" (68). Such a hypothesis (which would be lexical), is paired with input sensory data; this pair is given a value "which expresses the degree of confirmation" that the sense datum "bestows" upon the lexical hypothesis (68).

once the hypothesis is constructed and given a value, the input system can access a central system (e.g., memory) to confirm that the input may very well represent a panther or a convertible (often invoking a basic category), or a sentence type/logical linguistic form. This confirmation informs the subject what has been said, but not what has been meant.

Another way to view the module as an inferenceperforming system is in a premise/conclusion relationship: premises are "transduced representations of proximal stimulus configurations" (e.g., a transduction of information resulting from input of photons); conclusions are "representations of the character and distribution of 
distal objects" (e.g., a representation of a panther as it appears in the world of things) (42).

Central systems subsume modules and fixate belief (perceptual and non-perceptual) by monitoring what modules deliver, by accessing memory, and then by computing a "best hypothesis" concerning "what the world is like" (104).

The following is a list of some of the more important characteristics of central systems, many of which are the inverse of modular characteristics:

not hardwired/unstable: neuroanatomy

"relatively diffuse (118)

quasi assembled: a larger system composed of simpler systems

informationally unencapsulated: central systems access information from each other and from modules

domain neutral: "cut across cognitive domains" (101)

computationally global: may draw on other central systems or modules to perform operations

sensitive to belief system: during computation, central systems consider an individual's set of beliefs

isotropic: confirmation-relevant facts can be "drawn from anywhere in the field of previously established empirical truths"

Quineian: "the degree of confirmation assigned to any given hypothesis is sensitive to properties of the entire belief system; as it were, the shape of our whole science bears on the epistemic status of each scientific hypothesis" (107)

optional engagement: the operation of a central system is not necessarily mandatory, 
but can be elective

variable speed: may be very slow or instantaneous

Here, it is posited that the above described central systems may be thought of as central cognitive processes, i.e., specific central systems which possess distinguishing characteristics of their own while simultaneously possessing all the characteristics detailed above. 
VITA

The author, Frank A. Davis, is the son of Dutch and Belle (King) Davis. He was born in Morganfield, Kentucky, on February 20th, 1953.

Working in coal mines, Mr. Davis helped pay for his undergraduate education, earning a B.A. in government and Russian, cum laude, from Western Kentucky University in 1976. He also earned academic awards for best fiction and outstanding Russian student. Upon graduation, Mr. Davis served as a Lyndon Baines Johnson Intern in the U.S. Congress during the summer of 1976 .

In 1982, Mr. Davis graduated from the University of Arizona with a master of arts degree in English as a second language. From 1982 until 1985, Mr. Davis taught ESL at the University of Tennessee at Martin, where he also earned a best-fiction award.

As a fellow, Mr. Davis began doctoral studies in rhetoric and composition at Texas Christian University in 1985. At the University of Louisville, he focused on the linguistic aspects of composition, completing a doctorate in 1995 .

Mr. Davis teaches at Del Mar College in Corpus Christi, Texas. His wife, son, daughter, and he live in a rural environment outside the Corpus Christi metropolitan area. 